\title{
Knowing When to Use Stereotactic Ablative Radiation Therapy in Oligometastatic Cancer
}

\author{
Davide Franceschini ${ }^{1}$ \\ Maria Ausilia Teriaca' \\ Luca Dominici ${ }^{1}$ \\ Ciro Franzese ${ }^{1,2}$ \\ Marta Scorsetti ${ }^{1,2}$ \\ 'Department of Radiotherapy and \\ Radiosurgery, IRCCS Humanitas \\ Research Hospital, Milan, Italy; \\ ${ }^{2}$ Department of Biomedical Sciences, \\ Humanitas University, Milan, Italy
}

\begin{abstract}
Oligometastatic patients are a heterogeneous and yet not well-defined population. The actual definition identifies as oligometastatic, patients with 1-5 metastases in 1-3 different organs. However, only a proportion of these patients are "true" oligometastatic and therefore derive some kinds of benefit from local ablative approaches like stereotactic ablative radiation therapy (SABR). Since SABR is an easily accessible, effective and welltolerated treatment, it is widely employed in the oligometastatic scenarios, without a particular focus on selection criteria. However, it should be crucial to identify predictive and prognostic features that could be clinically implemented. Therefore, we conducted this narrative review of the available literature to summarize all clinical, radiomic, genetic and epigenetic features found to be predictive of overall survival, progression-free survival or local control of oligometastatic patients treated with SABR.
\end{abstract}

Keywords: stereotactic ablative radiation therapy, oligometastases, prognostic factors, selection criteria

\section{Introduction}

Despite 25 years have passed since the existence of an oligometastatic state was firstly postulate. ${ }^{1}$ The first clinical experiences of successful local treatment of metastatic patients are even older, being dated almost one century ago. ${ }^{2}$ Notwithstanding this quite impressive historical tradition and the constant increase in interest towards this clinical scenario in the last 20 years with hundreds of publications, very few step forwards were done for the identification of the "true" oligometastatic patient. A low number of metastases (one to five) in few organs (1 to 3) are still the most used definition for these patients. However, it is common thinking among the experts in the field that this numerical characterization is just a part of a more complex scenario, in which biological aspects, mostly still unknown, probably play a major role in determining the course of the disease. Recently, ESTRO and EORTC tried to standardize the definition of oligometastatic state according to available evidences, but the same authors conclude that much remains to be done for a more precise and accurate identification. ${ }^{3}$

Stereotactic ablative radiation therapy (SABR) is playing a crucial role in the treatment of oligometastatic patients. Although the first historical series are for the most part based on surgical metastasectomy, the most recent publications on the topic utilize SABR as the treatment of choice. There are different reasons for this trend in our opinion. Indeed, SABR is an effective and safe option (high local control rates and low toxicity reported in thousands of patients), and potentially feasible in almost
Correspondence: Maria Ausilia Teriaca Department of Radiotherapy and Radiosurgery, IRCCS Humanitas Research Hospital, via Manzoni 56, Rozzano, Milan, 20089, Italy

Tel +39028224746I

Email maria.ausilia.teriaca@cancercenter. humanitas.it 
all body sites. Moreover, SABR allows the simultaneous treatment of different lesions located in different organs, is non-invasive and does not require hospitalization. Lastly, but not less important, the large majority of oligometastatic patients treated with local ablative approaches in prospective trials are SABR patients, making SABR the only treatment with high level of evidence in this clinical scenario. ${ }^{4-7}$ However, the crucial question "who is the oligometastatic patient" is still to be answered. Therefore, in this review, we want to summarize the most recent findings in the identification of significant parameters for this clinical scenario. We chose to focus on the four major solid tumors (breast, lung, colorectal and prostate), looking not only for clinical features, but also with a special focus on biological, genetic and radiomic parameters that could enrich clinical evaluation.

\section{Materials and Methods}

A literature review of SABR in oligometastatic disease was performed. PubMed, Web of Science and MedLine were used for research.

Studies focusing on oligometastases treated with definitive SABR and reporting data on prognostic factors were included in the current analysis.

The following keywords were combined for the search: SABR/SBRT/stereotactic body radiotherapy AND oligometastases/oligometastatic AND pulmonary/lung OR prostatic/prostate OR colorectal OR breast cancer.

The correlation between prognostic factors and local control (LC), progression-free survival (PFS) and/or overall survival (OS) after SABR was evaluated.

\section{SABR-Related Predictors of Response in Primary Tumor-Specific Oligometastatic Disease Colorectal Cancer}

More than half patients with colorectal cancer (CRC) will develop metastatic disease despite definitive radical surgery at diagnosis. ${ }^{8,9}$ Among the local therapies, surgery is the most frequently used in oligometastatic disease. About $85 \%$ of patients with oligometastatic CRC have liver and lung localization and a surgical approach improves survival in this setting. ${ }^{10-13}$ SABR is an alternative ablative local therapy when surgery is not feasible or patients refuse metastasectomy. In a review of SABR in colorectal oligometastases, liver and lung 2-years LC rates were 32 $91 \%$ and $53-92 \%$, respectively. ${ }^{14}$ In a recent meta-analysis of CRC pulmonary metastases treated with SABR, Choi et al showed that LC rate at $1,2,3$, and 5 years was $81 \%$, $72 \%, 56 \%$, and $62 \%$, and the OS rate was $87 \%, 70 \%$, $58 \%$, and $43 \%$, respectively. ${ }^{15}$

The selection of patients who could benefit from local therapies is crucial in order to obtain the largest benefit from the treatments. However, factors related to long-term survival of CRC oligometastatic disease are not yet clearly defined in SABR setting.

We identified 16 articles reporting the analysis of prognostic factors after SABR in patients with CRC oligometastases. Two were prospective studies and 14 retrospective series. Overall, 1429 patients for a total of 2384 lesions were included. The details are described in Table 1.

According to our review, LC rates after SABR varied from $70 \%$ to $95 \%$ at 1 year and $64 \%$ to $81 \%$ after 3 years. Five series reported 5 -year LC rate ranging from $24 \%$ to $77 \%$. The OS rates ranged from $67 \%$ to $95.5 \%$ at 1 year. The 3- and 5-year OS rates were $43-57 \%$ and $26-43 \%$, respectively. PFS ranged from $37 \%$ to $56 \%$ at 1 year and $64 \%$ to $81 \%$ after 3 years.

Treatment-related factors affecting $\mathrm{LC}$ and survival were doses. In particular, biological effective dose (BED) $\geq 100$ predicted better LC in 5 series $^{16-20}$ and BED $\geq 75$ in one study. ${ }^{21}$ Sharma et al observed poorer LC in patients treated with $\mathrm{BED}<100 .^{22}$ Only two studies found correlation between higher OS and BED $>100 .{ }^{20,22}$ In a prospective trial, LC was better in patients treated with SABR dose $\geq 60$ Gy in 3 fractions at univariate analysis $(p=0.04) .{ }^{23}$ SABR dose also improved LC in a little retrospective study. ${ }^{24} \mathrm{CRC}$ metastases are assumed to be radioresistant and it may explain why higher doses related to better outcomes. Volume of metastases correlated with LC in 3 series ${ }^{21,24,25}$ and with OS in 6 studies. ${ }^{19,23,25-28}$ Total number of metastases treated with SABR was not a clear prognostic factor according to our analysis. Limited number $(<3)$ of metastases improved LC in one study ${ }^{29}$ and OS in two. ${ }^{22,28}$ In a retrospective study LC was significantly better for pulmonary oligometastases from rectal cancer compared to those from colon cancer. ${ }^{17}$ The reason is unknown. The same authors concluded that this difference in response could be due to the heterogeneous molecular patterns between the two primary sites such as microsatellite instability, BRAF/KRAS status, etc. Lung location was correlated with better LC than liver metastases also in Thomson et al study. ${ }^{19}$ The liver microenvironment which gives a higher tumor radioresistance may be 


\begin{tabular}{|c|c|c|c|c|}
\hline & 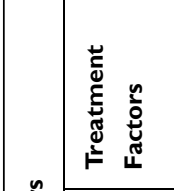 & 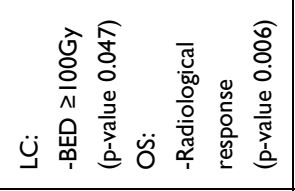 & 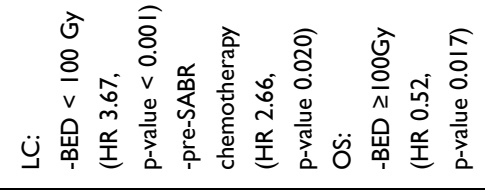 & 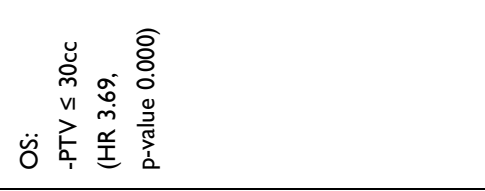 \\
\hline & 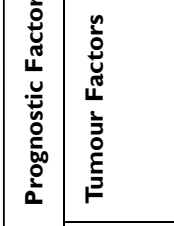 & $\stackrel{i}{i}$ & 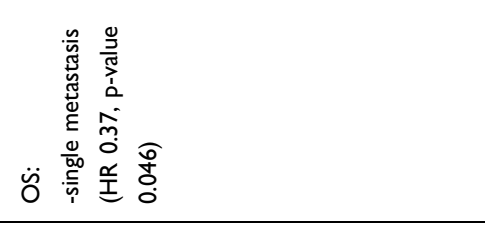 & 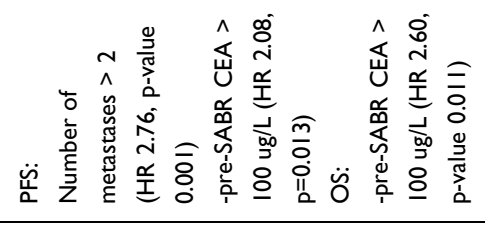 \\
\hline & 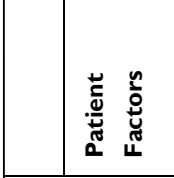 & $\stackrel{i}{Z}$ & 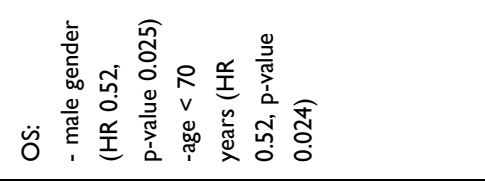 & 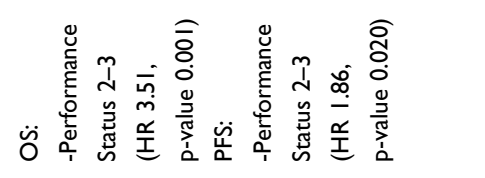 \\
\hline & $\frac{n}{2}$ & $\stackrel{i}{z}$ & 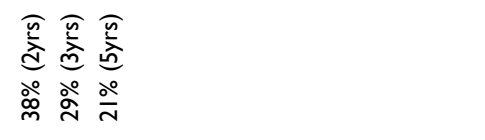 & 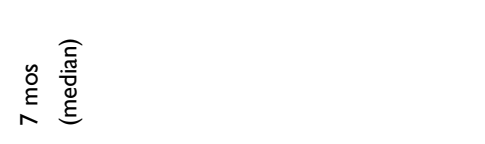 \\
\hline & ๕ & 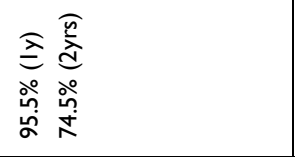 & 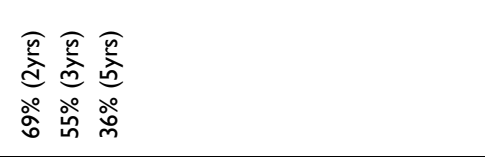 & 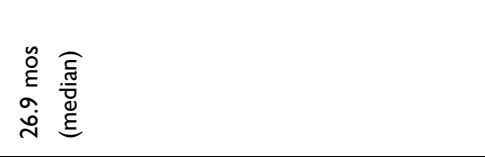 \\
\hline & צ & 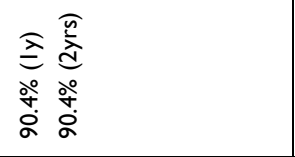 & 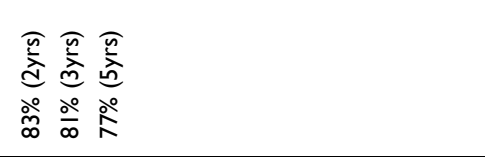 & 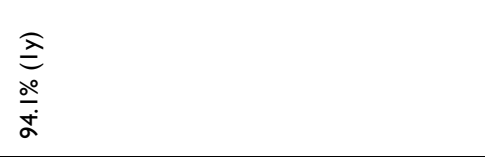 \\
\hline & 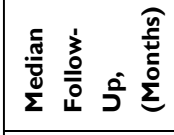 & \pm & $\bar{m}$ & 总 \\
\hline & 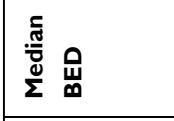 & $\begin{array}{l}\hat{0} \\
\underline{8} \\
\end{array}$ & $\frac{\pi}{z}$ & $\begin{array}{l}\hat{0} \\
\underline{8}\end{array}$ \\
\hline & 秀 & 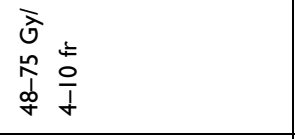 & $\stackrel{\leftrightarrow}{z}$ & $\stackrel{i}{z}$ \\
\hline & 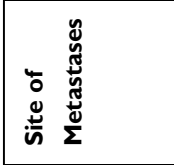 & $\stackrel{\infty}{\Xi}$ & 些 & 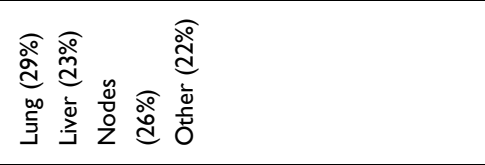 \\
\hline & 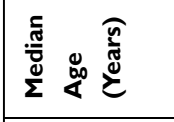 & $\bar{\sigma}$ & $\frac{1}{z}$ & $\bar{\sigma}$ \\
\hline & 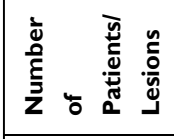 & 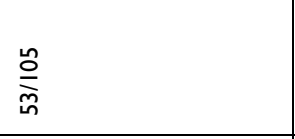 & 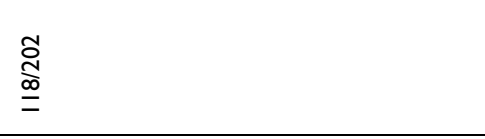 & $\frac{2}{\frac{\alpha}{2}}$ \\
\hline & 害高 & 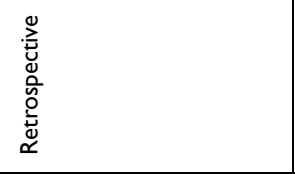 & 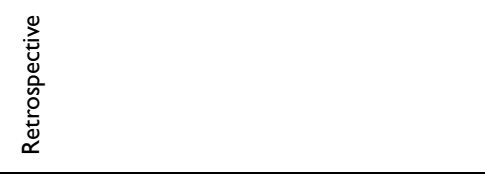 & 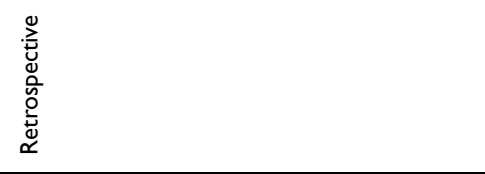 \\
\hline & 离 & 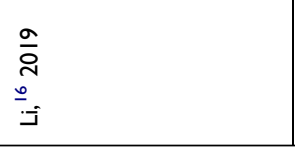 & 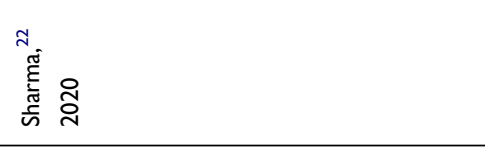 & 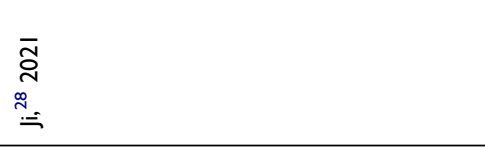 \\
\hline
\end{tabular}




\begin{tabular}{|c|c|c|}
\hline 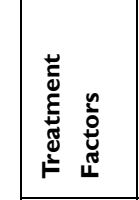 & 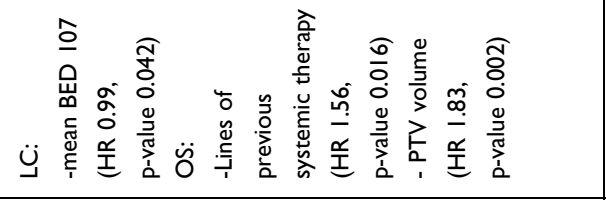 & 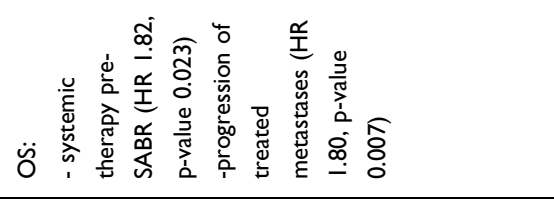 \\
\hline 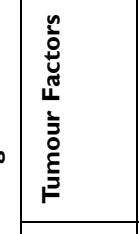 & 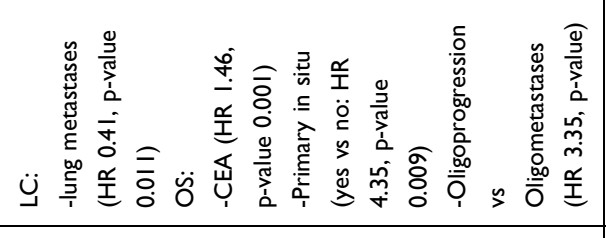 & 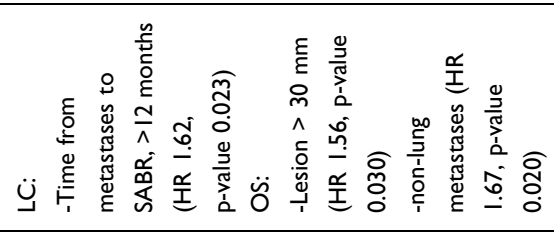 \\
\hline 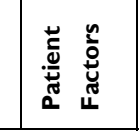 & $\frac{\pi}{Z}$ & $\stackrel{\mathscr{S}}{z}$ \\
\hline & 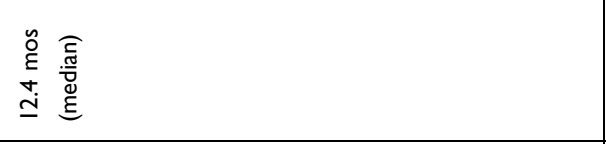 & 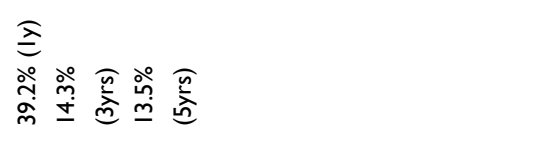 \\
\hline & 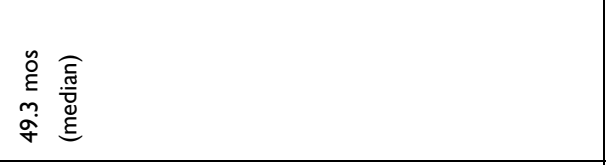 & 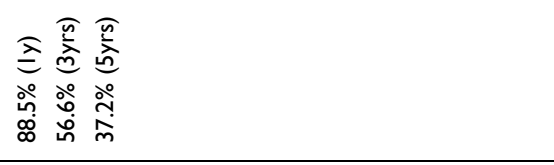 \\
\hline & 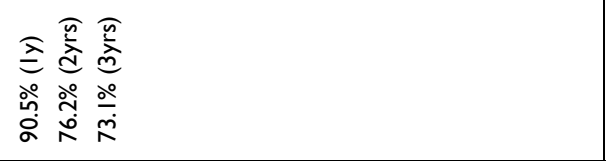 & 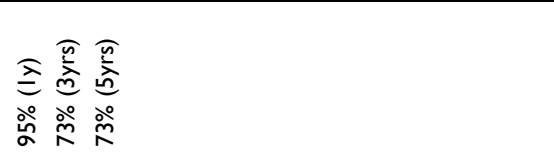 \\
\hline 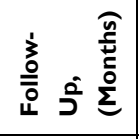 & $\pi$ & $\approx$ \\
\hline 욨 & $\begin{array}{l}\widehat{\widehat{o}} \\
\hat{\underline{b}}\end{array}$ & 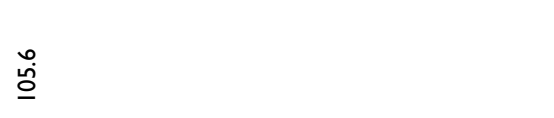 \\
\hline 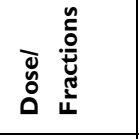 & 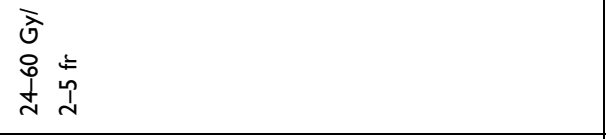 & 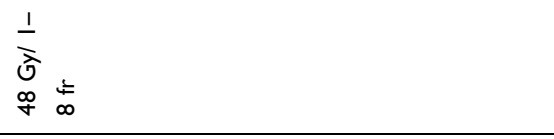 \\
\hline & 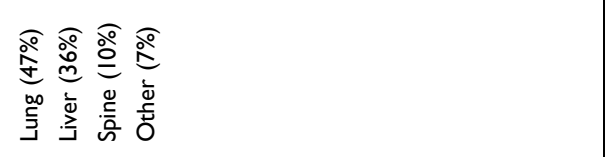 & 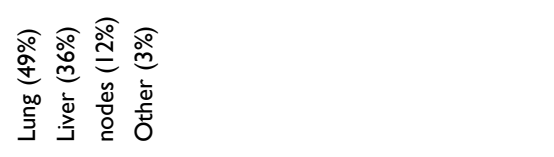 \\
\hline 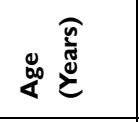 & อ & o \\
\hline 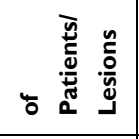 & 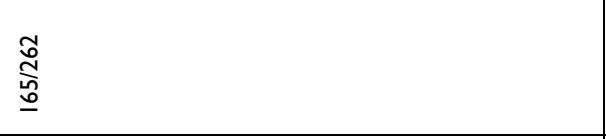 & 商 \\
\hline $\begin{array}{l}\frac{50}{5} \\
\text { on } \\
\end{array}$ & 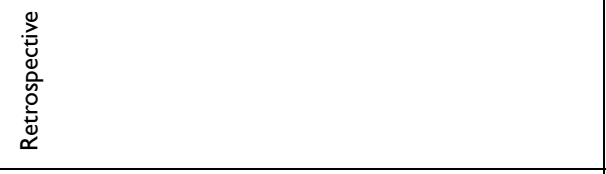 & 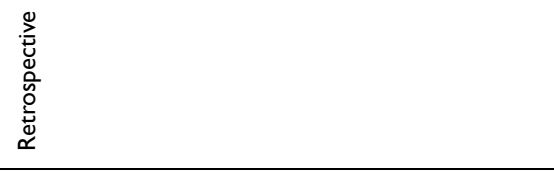 \\
\hline$\nu^{\infty}$ & 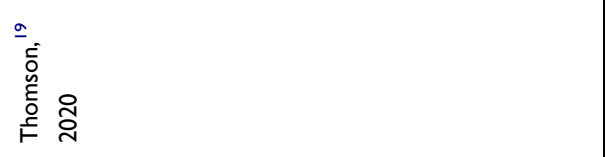 & 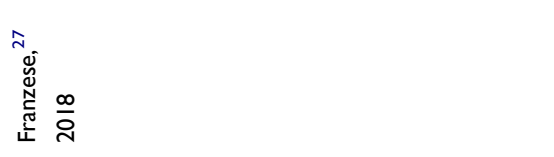 \\
\hline
\end{tabular}




\begin{tabular}{|c|c|c|c|}
\hline 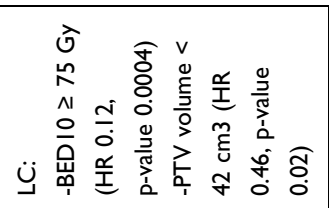 & $\stackrel{\Delta}{z}$ & $\stackrel{\leftrightarrow}{\check{z}}$ & 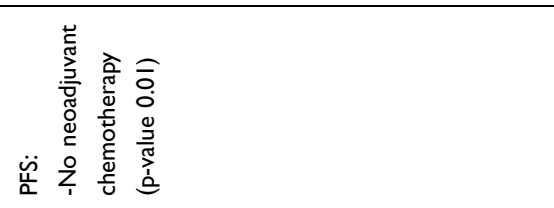 \\
\hline$\overleftrightarrow{\Delta}$ & 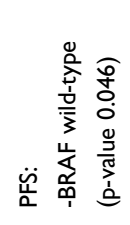 & 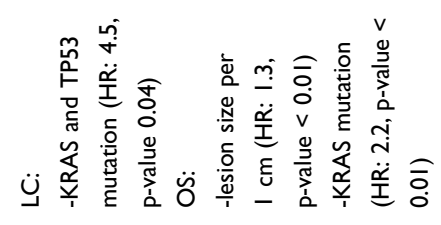 & 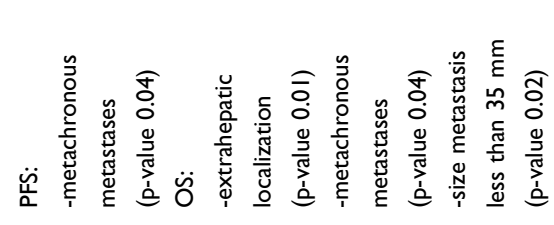 \\
\hline$\stackrel{1}{z}$ & $\frac{\pi}{z}$ & 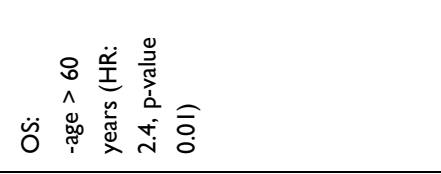 & 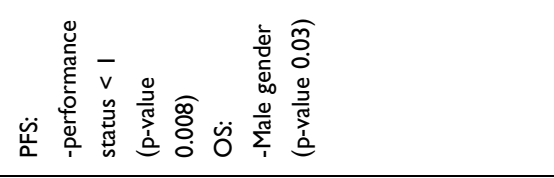 \\
\hline 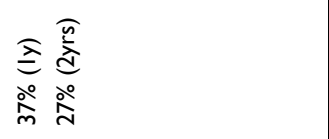 & 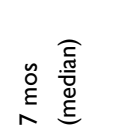 & 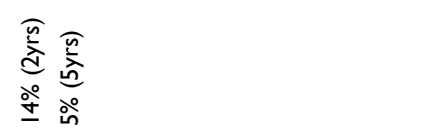 & 这 \\
\hline 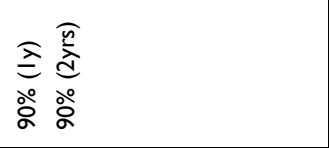 & 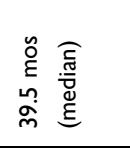 & 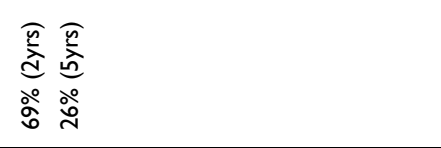 & 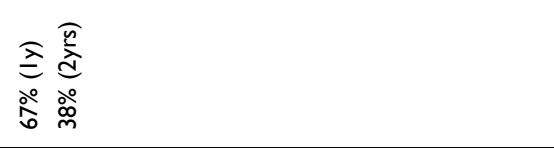 \\
\hline 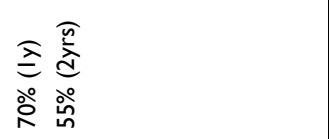 & 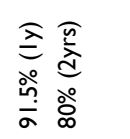 & 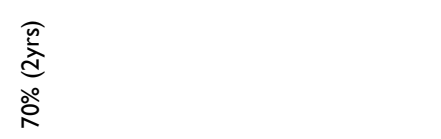 & 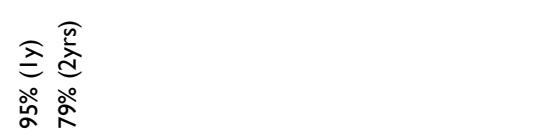 \\
\hline$\stackrel{+}{=}$ & $\stackrel{\infty}{\sim}$ & in & \pm \\
\hline$\stackrel{\stackrel{n}{I}}{=}$ & $\underline{\underline{\underline{O}}}$ & $\stackrel{m}{=}$ & $\stackrel{i}{Z}$ \\
\hline f & 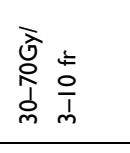 & $\begin{array}{l}n \\
\text { no } \\
\hat{0} \\
0 \\
0\end{array}$ & $\begin{array}{l} \pm \\
m \\
0 \\
\hat{0} \\
y \\
\end{array}$ \\
\hline 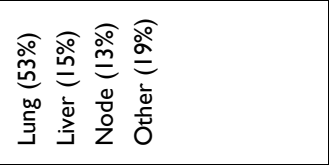 & 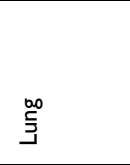 & 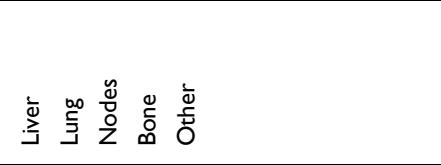 & 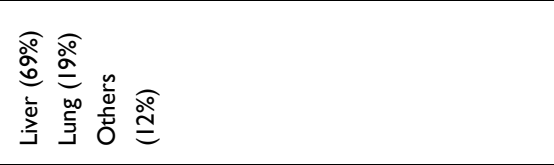 \\
\hline ఠิ & 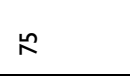 & $\stackrel{\infty}{\infty}$ & $\hat{\imath}$ \\
\hline 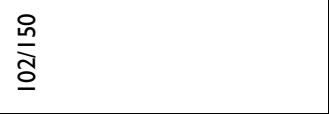 & $\frac{\hat{o}}{\mathrm{o}}$ & 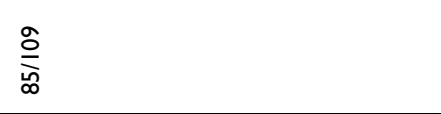 & $\frac{\bar{f}}{f}$ \\
\hline 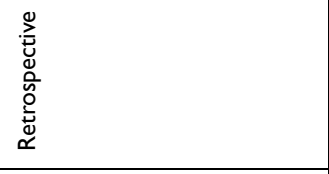 & 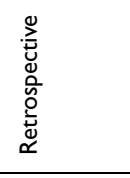 & 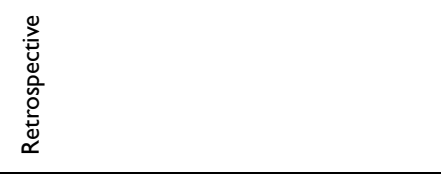 & 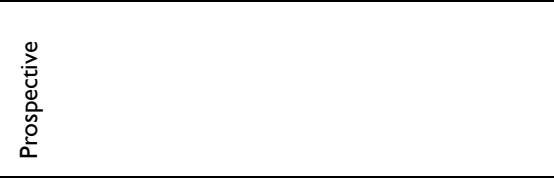 \\
\hline 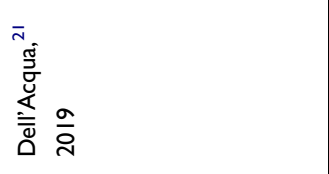 & 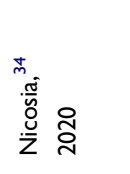 & 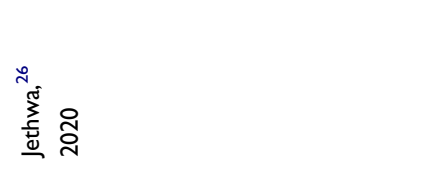 & 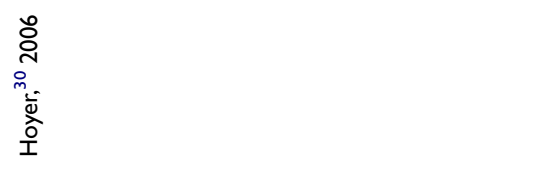 \\
\hline
\end{tabular}




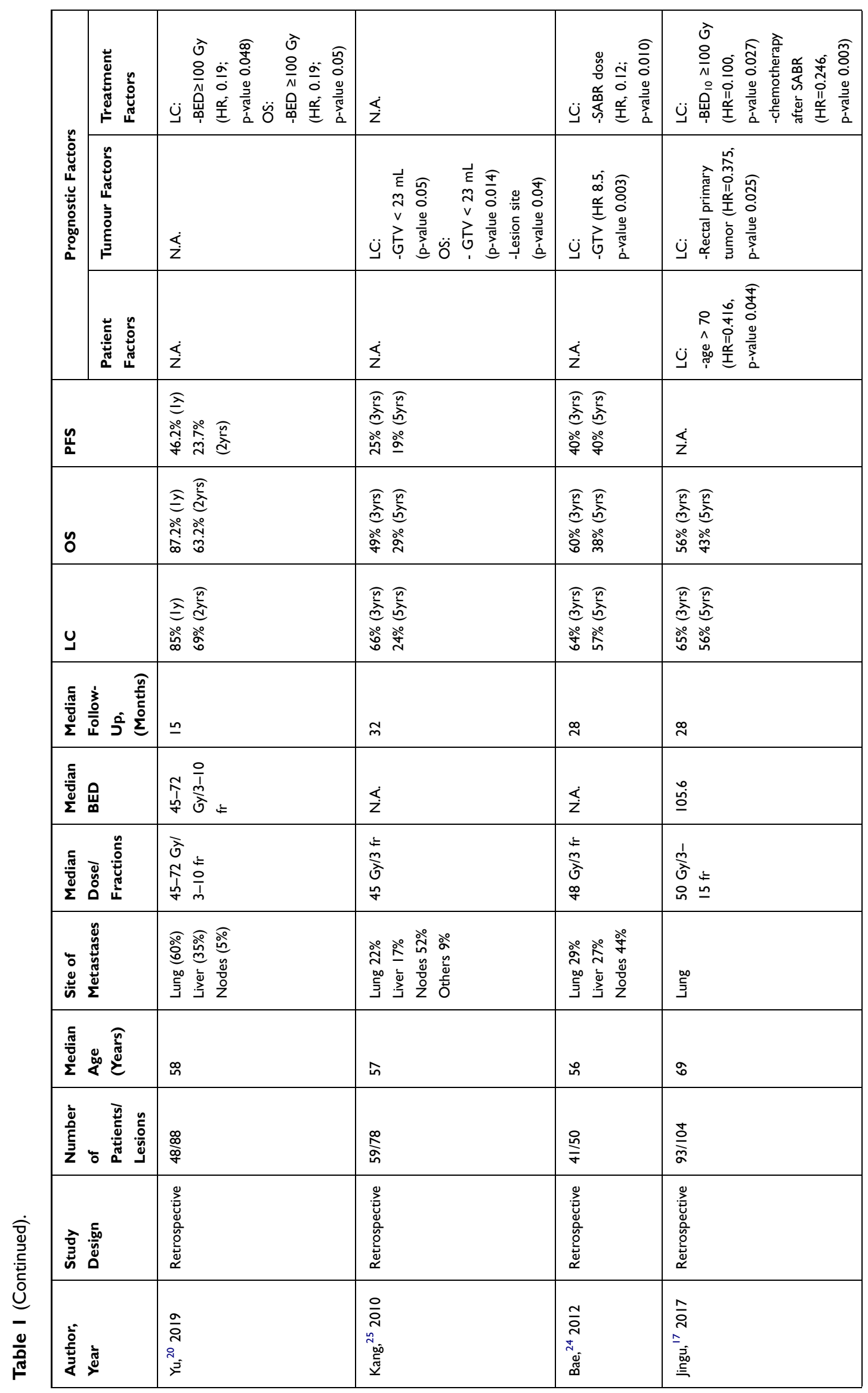




\begin{tabular}{|c|c|c|}
\hline 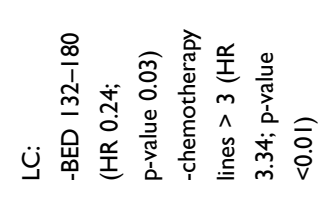 & 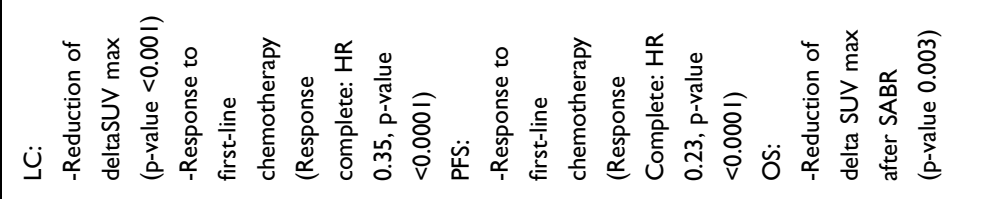 & 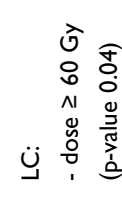 \\
\hline 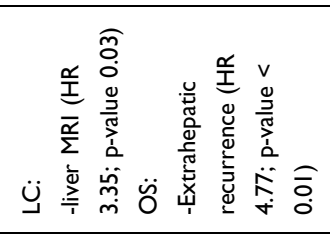 & 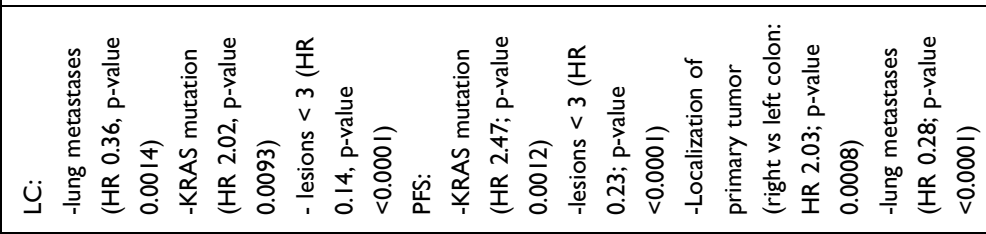 & 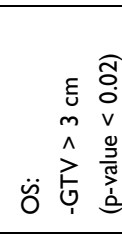 \\
\hline 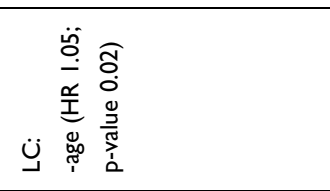 & $\stackrel{i}{Z}$ & $\stackrel{i}{z}$ \\
\hline 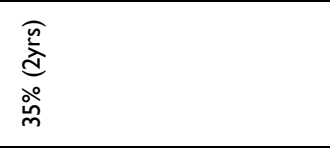 & 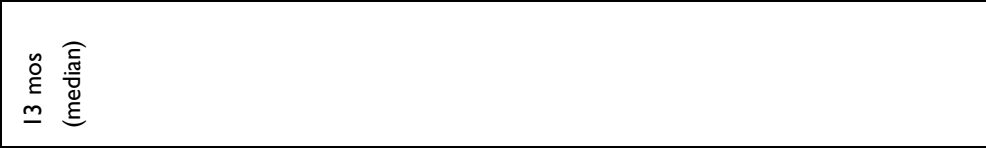 & 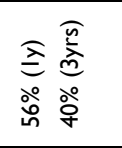 \\
\hline 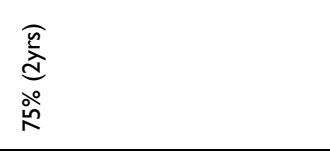 & 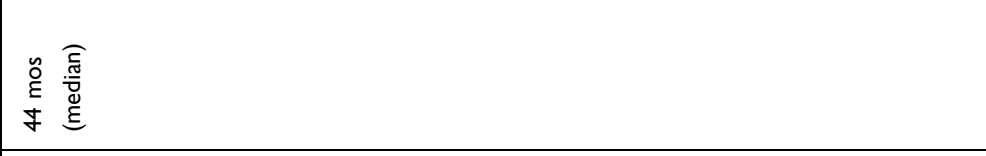 & 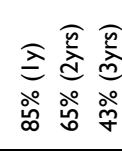 \\
\hline 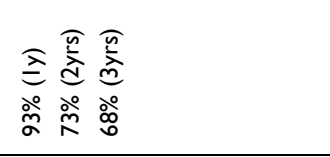 & $\frac{\pi}{2}$ & 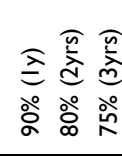 \\
\hline 赵 & $\begin{array}{l}\text { 监 } \\
\end{array}$ & I \\
\hline$\frac{\alpha}{b}$ & $\underline{\otimes}$ & $\frac{d}{z}$ \\
\hline 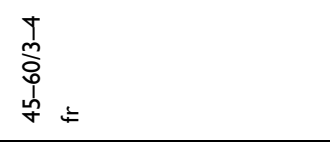 & $\begin{array}{l}1 \\
0 \\
0 \\
\hat{0} \\
0 \\
0\end{array}$ & 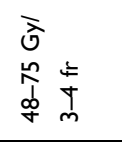 \\
\hline$\stackrel{\text { ڤે }}{3}$ & 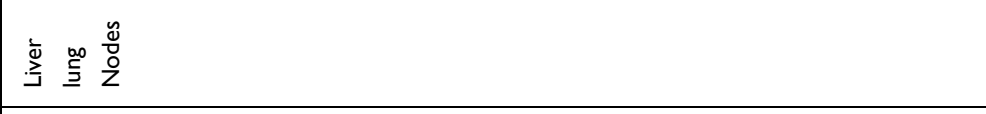 & 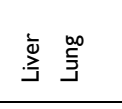 \\
\hline ๑ & 5 & $\stackrel{\infty}{\infty}$ \\
\hline 产 & 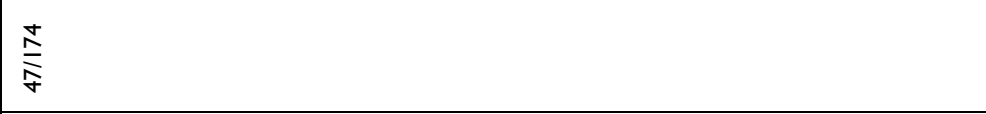 & $\stackrel{\infty}{\equiv}$ \\
\hline 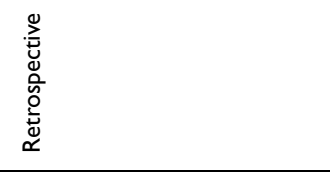 & 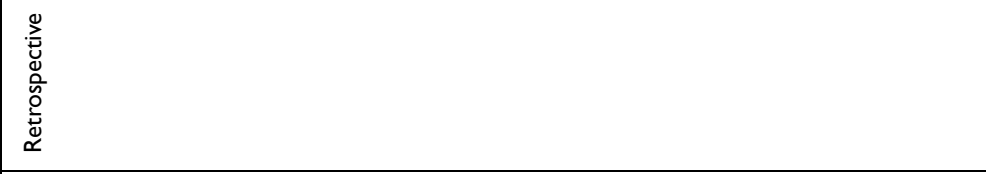 & 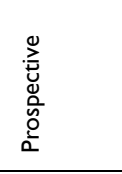 \\
\hline $\begin{array}{l}\hat{\bar{c}} \\
\underline{\infty} \\
\underline{0} \\
\underline{0} \\
\end{array}$ & 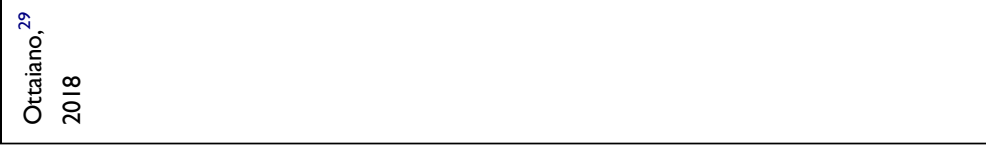 & 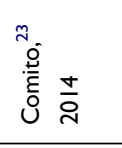 \\
\hline
\end{tabular}


the reason for this. The difficulty of finding all liver lesions on Cone Beam Computed Tomography (CBCT) was another explanation reported by authors. The same result was reported in another retrospective analysis. ${ }^{29}$ Franzese et al showed that non-lung metastases predicted poor OS in a large retrospective study. ${ }^{27}$ The metachronous timing of metastases was a positive prognostic factor for OS and PFS in a Phase II trial. ${ }^{30}$ Sixty-four patients with 141 metastases were included. Male gender, extrahepatic localization and size of the metastasis less than $35 \mathrm{~mm}$ were also significantly correlated with better OS on univariate analysis. Advanced age was an unfavorable prognostic factor in oligometastases disease treated with SABR in 3 retrospective series. ${ }^{17,22,26}$ The role of chemotherapy in CRC oligometastases treated with SABR is unclear. Thomson et al reported that number of lines of previous systemic therapy improved OS, ${ }^{19}$ while it was a poor prognostic factor in Franzese et al analysis. ${ }^{27}$ Similarly, poor LC was correlated to pre-SABR chemotherapy in a large retrospective study of CRC pulmonary metastases. ${ }^{22}$ A complete response after first-line of chemotherapy at radiologic evaluation improved PFS in a retrospective study. ${ }^{29}$ The conflicting results on preSABR systemic therapy could be related to the retrospective nature of these studies and patients selection bias. Furthermore, Jingu et al showed in multivariate analysis that chemotherapy after SABR improved LC in pulmonary oligometastatic disease from CRC. ${ }^{17}$ Usually, response to SABR is assessed by Computed tomography (CT) or Magnetic Resonance Imaging (MRI). However, the [18F]-fluorodeoxyglucose positron emission tomography computed tomography ([18F]-FDG-PET/CT) is often used to discriminate necrotic tumor tissue from actively replicating tumor tissue after SABR. An Italian retrospective study investigated the role of [18F]-FDG-PET/CT among prognostic factors after SABR in patients with metastatic colorectal cancer. Notably, all patients were evaluated by [18F]-FDG-PET/CT before and after SABR and the reduction in delta maximum standardized uptake value $\left(\mathrm{SUV}_{\max }\right)$ was significantly correlated with $\mathrm{LC}>12$ months $(\mathrm{p}<0.001)$ and $\mathrm{OS}>24$ months $(\mathrm{p} 0.003)$ at analysis. ${ }^{29} \mathrm{Li}$ et al reported a correlation between radiological response to CT-scan and OS after SABR. The first radiology evaluation was at a median time of 1.8 months (0.5-8.0, range) and the second at 5.3 months (1.9-12.5, range). The 2-years OS rate was correlated with radiological response at second assessment (Complete Response vs Partial Response vs Stable Disease vs Progressive Disease: 100 vs 85.7 vs 53.3 vs $25 \%$; $\mathrm{P}=0.006) .{ }^{16}$

Biomarker-based patient selection could be the right way to proceed, however published studies are rare. ${ }^{31-33}$ Pitroda et al classified patients with CRC liver metastases into 3 subgroups based on a molecular risk score. ${ }^{31}$ Patients with immune activation, p53 pathway and NRAS mutation had better OS. KRAS signaling, angiogenesis and SMAD3 mutation correlated with worse survival. The intermediate subgroup showed activation of E2F/MYC signaling, DNA damage and NOTCH1 and PIK3C2B mutations. Narayan et al reported poor diseasespecific survival if peripheral circulating tumor DNA with TP53 mutation was found prior to resection of CRC liver metastases. $^{32}$ In a review of resectable and unresectable colorectal liver metastases, KRAS and BRAF mutations were a negative prognostic factor for survival. ${ }^{33}$ According to our review, KRAS and TP53 mutations correlated with worse survival outcomes including OS in CRC oligometastases treated with SABR. ${ }^{26,29}$ Nicosia et al found at univariate analysis that BRAF wildtype status was predictive for a longer local progression-free survival. $^{34}$

\section{Prostate Cancer}

Androgen deprivation therapy (ADT), chemotherapy and palliative or ablative radiotherapy, alone or combined, are among the therapeutic strategies in metastatic prostate cancer $(\mathrm{PCa}){ }^{35,36}$ As two randomized trials have shown, therapeutic approach to use depends on the tumor burden. $^{37,38}$ According to CHARTEED trial, ADT combined with docetaxel resulted in improved OS compared to ADT alone in patients with high-volume metastatic PCA. Notably, the authors defined "high-volume" as presence of visceral metastases and/or more than 4 bone metastases (at least one outside of spine and pelvis). ${ }^{37}$ On the other hand, LATITUDE trial defined the high tumor burden as a highrisk disease characterized by at least 2 of the following criteria: Gleason score $\geq 8$, number of lesions $\geq 3$ on bone scan, presence of measurable visceral lesion. In this setting, Abiraterone Acetate (AA) plus prednisone associated with ADT showed better OS than ADT alone. ${ }^{38}$ On the contrary, PCa oligometastatic disease has a limited tumor burden (presence of up to 3-5 metastases) and may benefit from use of metastases-directed therapy (MDT). ${ }^{39}$ In particular, the use of surgery or SABR in PCa oligometastases could delay the progression of the disease, postpone the start of systemic therapy and improve the patient's quality 
of life and survival. ${ }^{40,41}$ In a prospective trial, Ost et al showed a median ADT-free survival of 21 months for patients undergoing MDT (SABR or surgery) compared to 13 months for the surveillance group in PCa oligometastatic disease with $\leq 3$ lesions. ${ }^{6}$

Nine studies reporting data on prognostic factors for PCa oligometastases treated with SABR were included in the current analysis. Seven were retrospective studies and 2 were prospective. A total of 1471 lesions treated with $\mathrm{SABR}$ in 916 patients were evaluated. The details are described in Table 2.

The LC rates in these studies are highly variable: some authors reported the data at 1,2, 3 or 5 years, others even at 6 months or 18 months. In 2 cases, the LC is not reported. ${ }^{42,43}$

According to our review, majority of SABR studies only investigate LC and PFS, and not OS. Patients with PCa have a long survival and OS is rarely analyzed in most studies. PFS represents a valid surrogate endpoint. Only one study reported 5-years LC, OS e PFS rates, ${ }^{44}$ which were $92 \%, 88 \%$ and $15 \%$, respectively. All 9 studies assessed PFS among outcomes, but its definition was not the same. Increased Prostate Specific Antigen (PSA) may be a sign of progression even in the absence of radiological or clinical evidence of disease. Schick et al reported biochemical relapse-free survival as a surrogate of PFS (bRFS). ${ }^{42}$ They described biochemical recurrence as an increase in PSA value $>1 \mathrm{ng} / \mathrm{mL}$. In another prospective trial, the primary endpoint was the treatment escalationfree survival (TE-FS). ${ }^{43}$ It was defined as initiation of ADT, chemotherapy or palliative radiation therapy following PSA recurrence, radiological progression, or onset of symptoms.

Prognostic LC-related factors were described in 2 studies. Franzese et al showed that oligoprogressive versus oligorecurrent patients correlated with worse LC at univariate analysis. However, the 2 groups were unbalanced and $97 \%$ of patients had oligorecurrent disease. Time to SABR was also associated with poor LC. ${ }^{45}$ BED $<100$ predicted a higher local recurrence rate at 3 years in a multi-institutional retrospective analysis of $119 \mathrm{PCa}$ patients. $^{44}$ The role of BED $>100$ in improving outcome was also highlighted for PFS. ${ }^{46,47}$ A normalized total dose $>64$ Gy improved three-year bRFS in PCa patients with less than five metastases treated by SABR and ADT. ${ }^{42}$ Bowden et al reported 5-year follow-up of a prospective phase II study evaluating SABR for oligometastatic PCa patients with up to 5 lesions. SABR was delivered in 199 patients, $82.9 \%$ of whom had up to 3 lesions. At median follow-up of 35.1 months, prior ADT and increasing age correlated with poor TE-FS. ${ }^{43}$ Opposite results were shown by Jereczek-Fossa et al at multivariate analysis: age over 75 years and ADT administration for up to 12 months were associated with a longer PFS. Pelvic lymph nodes involvement and pre-SABR PSA $<10 \mathrm{ng} / \mathrm{mL}$ were the other factors that improved PFS. ${ }^{48}$ These differences 2 studies could be partially explained by their opposite nature, one prospective and the other retrospective, and by selection of patients. In the prospective trial, the same authors commented that many patients probably had occult poly-metastases at the time they started ADT. This plausibly led to early disease relapse.

Use of ADT before SABR was related to worse OS in a retrospective study on 92 patients (HR 1.16, 95\% CI 7.55-17.9; $p=0.000$ ). In addition, PSA velocity (defined as annual increase of PSA) correlated with poor PFS (HR $1.01,95 \%$ CI $1.00-1.02, \mathrm{p}=0.049){ }^{49}$

With recursive partitioning analysis, the patients were stratified into risk groups based on OS and PFS. Castration-sensitive group was related with better 3-years OS $(p=0.0003)$. PFS was longer in patients with diseasefree interval $\geq 34$ months and low-intermediate risk disease (3 years PFS of $60.2 \%, p=0.016$ ).

A multi-institutional retrospective study evaluated 176 oligometastatic PCa patients (pts) treated by MDT (SABR in 129 pts or convention radiotherapy in $47 \mathrm{pts}$ ) based on Gallium-68-labeled prostate-specific membrane antigen (PSMA) PET. An increased number of metastases related to poor $\mathrm{OS}(\mathrm{HR}=1.44, \mathrm{p}=0.02)$ at multivariate analysis. Untreated primary PCa was negative predictor of both PFS (HR 2.22, p 0.03) and OS (HR 3.3, p 0.02). Finally, MDT with conventional fractionation was associated with worse PFS compared to SABR (HR $3.80 \mathrm{p}<0.001$ ). ${ }^{47}$

In oligometastatic $\mathrm{PCa}$, sensitivity or not to castration was a factor influencing PFS after SABR in a retrospective study. ${ }^{45}$ In particular, poor PFS was observed in metastatic castration-resistant PCa (mCRPC) (HR 2.12; p 0.02). The cause is uncertain. However, in patients with $\mathrm{mCRPC}$ at the time of SABR there may be a subclinical disease, which will become evident soon after treatment, making the research for the right combination of SABR and systemic therapy crucial. The ARTO trial is an ongoing phase II randomized study investigating the role of ablative radiation therapy in addition to next-generation hormone therapy (AA) in patients with metastatic castration-resistant $\mathrm{PCa}{ }^{50}$ At 6-month follow-up, an interim analysis was 


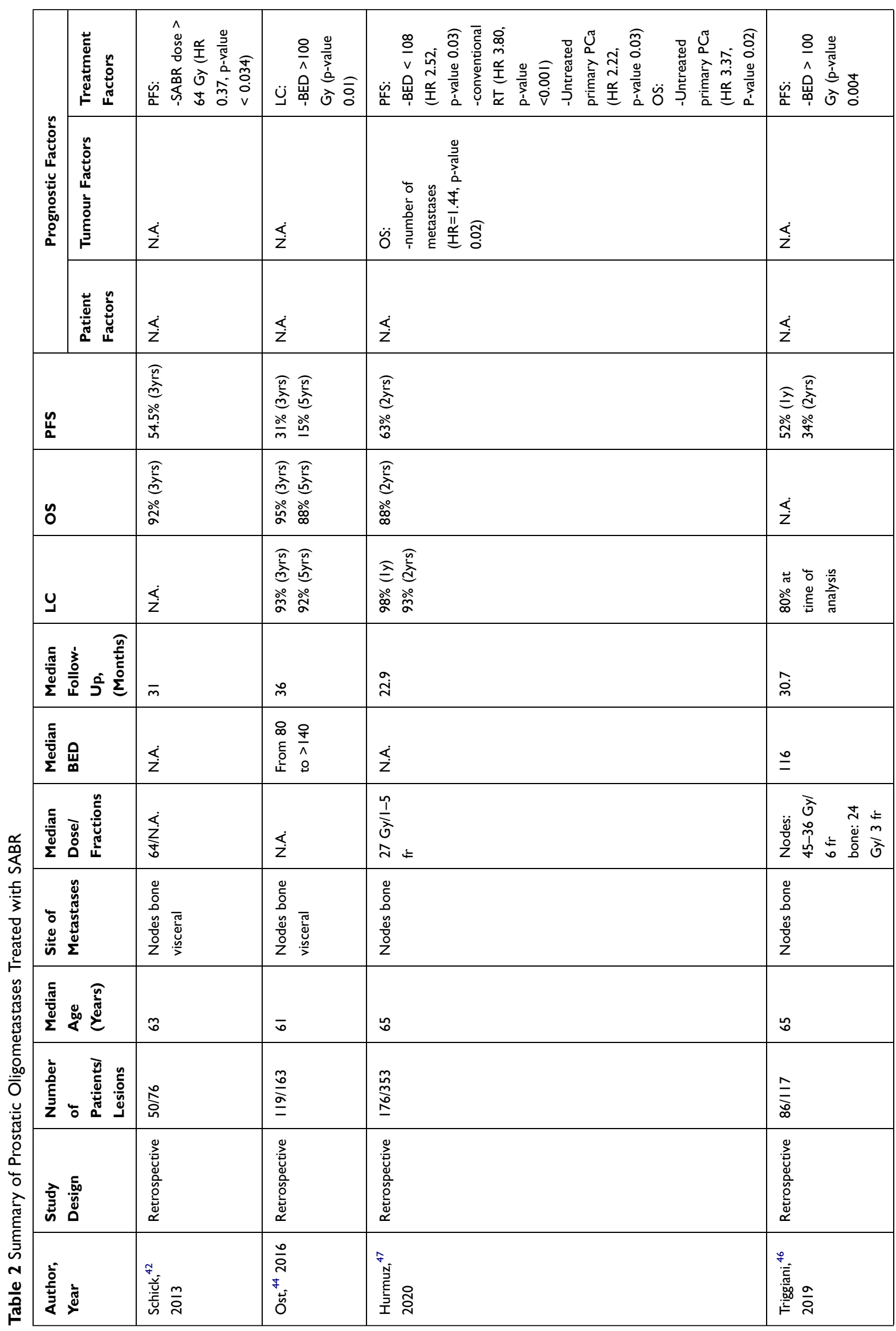




\begin{tabular}{|c|c|c|c|c|}
\hline 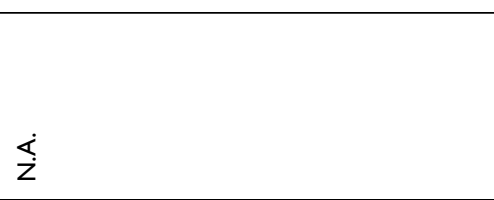 & 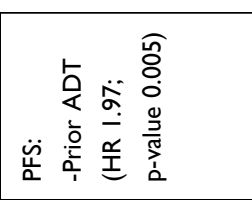 & 芒 & 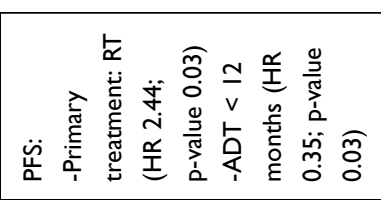 & 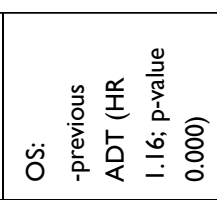 \\
\hline 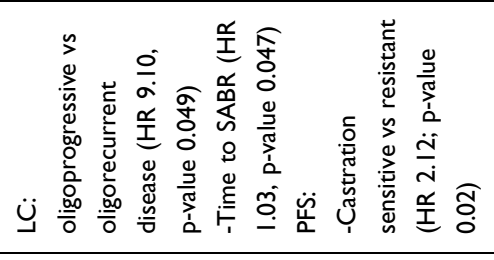 & 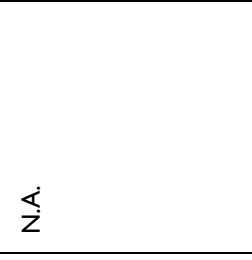 & 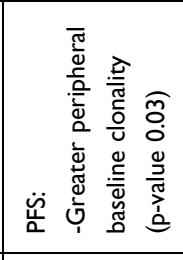 & 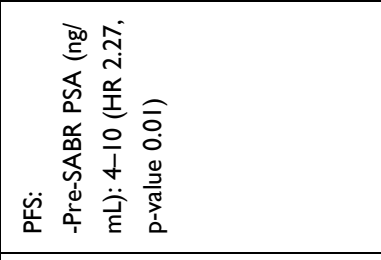 & 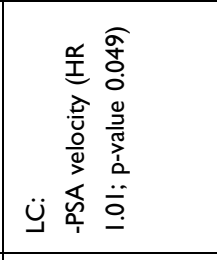 \\
\hline ¿̇ & 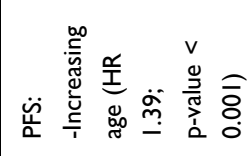 & 这 & 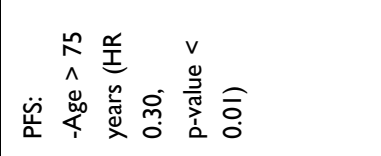 & $\stackrel{\Delta}{Z}$ \\
\hline 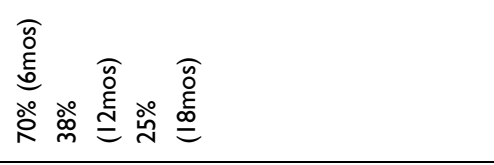 & 总 & 尊 & 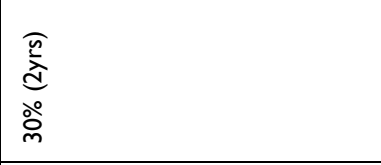 & 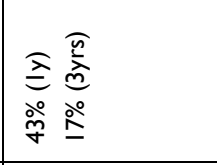 \\
\hline 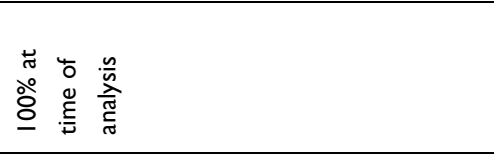 & 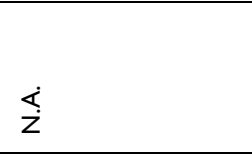 & 芒 & $\stackrel{\mathbb{Z}}{\mathrm{Z}}$ & 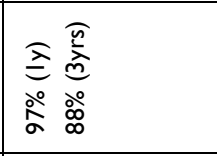 \\
\hline 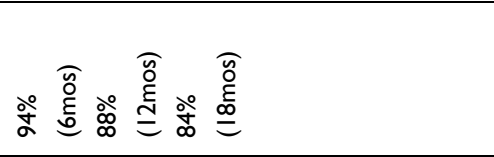 & $\stackrel{\mathbb{Z}}{\mathrm{z}}$ & 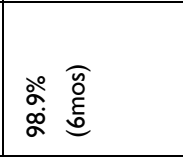 & 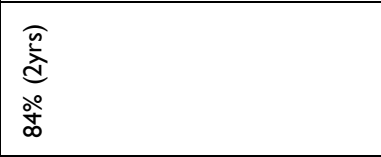 & 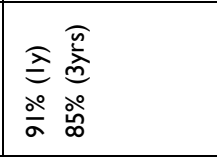 \\
\hline$\underline{\text { ñ }}$ & $\overline{\dot{\rho}}$ & 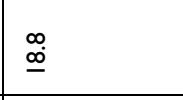 & $\begin{array}{l}\stackrel{\stackrel{\sim}{0}}{\underline{0}} \\
\end{array}$ & $\tilde{z}$ \\
\hline in & $\stackrel{\Delta}{Z}$ & 妾 & $\underline{\tilde{n}}$ & 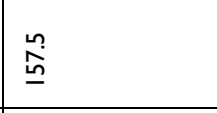 \\
\hline 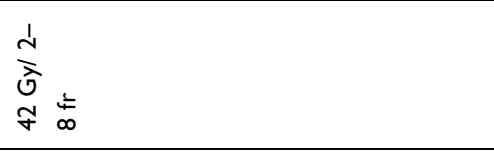 & 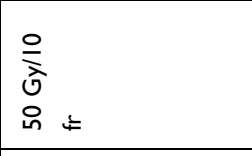 & 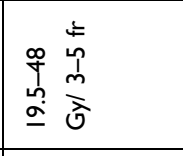 & 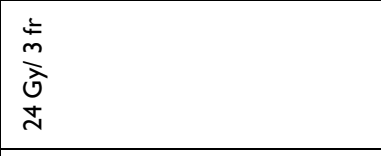 & 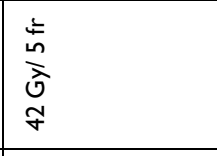 \\
\hline 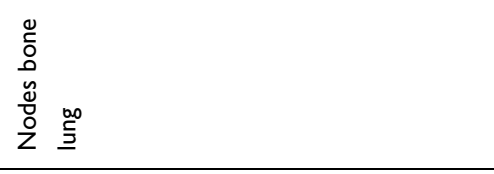 & 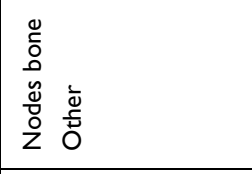 & 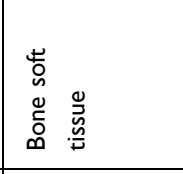 & $\begin{array}{l}\text { yov } \\
\text { ò } \\
\end{array}$ & 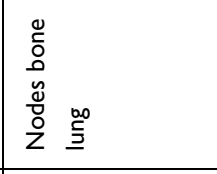 \\
\hline$\approx$ & 6 & $\stackrel{\infty}{\circlearrowleft}$ & 2 & $\pi$ \\
\hline$\frac{8}{4}$ & 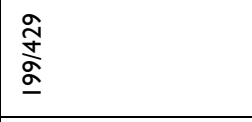 & 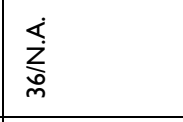 & 紊 & ڤু \\
\hline 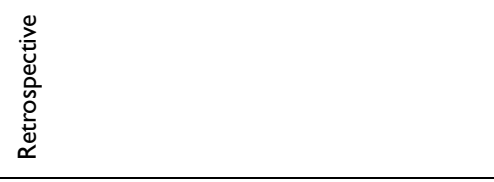 & 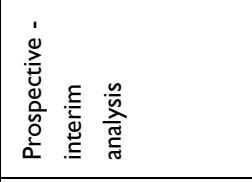 & 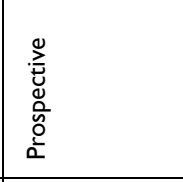 & 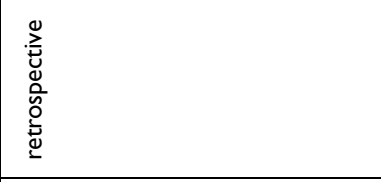 & 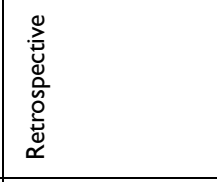 \\
\hline 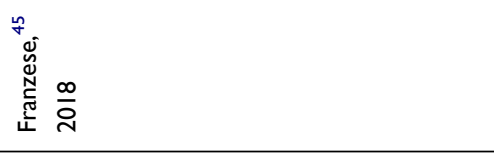 & 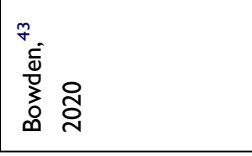 & 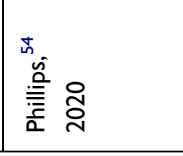 & 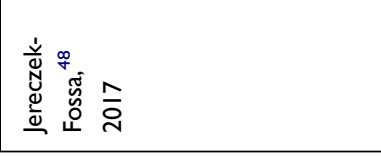 & 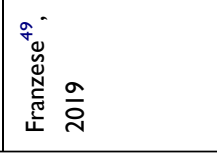 \\
\hline
\end{tabular}


recently presented. The treatment group (SABR + AA) consisted of 13 patients and the control group (AA) of 18 patients. In the treatment group, complete response (PSA level $<0.2 \mathrm{ng} / \mathrm{dL}$ ) and biochemical response (PSA reduction $>50 \%$ from baseline) were observed in $46 \%$ and $77 \%$, respectively. In the control group, the same were achieved in $22 \%$ and $44 \%$, respectively. ${ }^{51}$

More advanced tests such as the count of circulating tumor cells (CTC) or the evaluation of genomic aberrations in circulating tumor DNA (ctDNA) can be useful for the identification of the oligometastatic patient who can benefit from MDT and therefore from SABR. However, the clinical use and practical application of genomic markers in the oligometastatic setting is unclear because solid data is lacking.

A recent review focused on role of blood-based liquid biopsy in metastatic $\mathrm{PCa} .{ }^{52}$ The authors observed that both CTC count and ctDNA could be prognostic factors in metastatic PCa predicting patient resistance to treatment. In the CTC count, the presence of androgen receptor splice variant 7 (AR-V7) was a biomarker for resistance to treatment with Abiraterone/Enzalutamide/Apalutamide (androgen receptor-targeted therapy) in mCRPC. Also, the aberrations of the androgen receptors present in the ctDNA were predictors of a poor response to the aforementioned drugs in mCRCP. On the other hand, AR-V7 correlated with a better response to chemotherapy.

Recently, Bjerre et al investigated the use of ctDNA in de novo metastatic PCa. Three methylation markers (DOCK2/HAPLN3/FBXO30) were elevated in highvolume versus low-volume metastatic PCa $(\mathrm{p}<0.001)$. Furthermore, methylated ctDNA was associated with rapid progression of hormone-naïve disease. ${ }^{53}$ The ORIOLE Phase 2 randomized trial investigated oligometastatic patients with hormone-sensitive PCa enrolled to received SABR or observation. ${ }^{54}$ Clonal expansion of T-cell receptors was found in the SABR arm after ablative treatment. The baseline clonality related to progression after SABR (p 0.03). In addition, all patients who received SABR to all lesions detectable by PSMA PET had better metastasisfree survival and PFS $(p=0.006)$.

\section{Lung Cancer}

At the time of diagnosis in patients with non-small-cell lung cancer (NSCLC) metastatic disease occurs in about half of cases, and the most frequent presentation, after progression in patients with localized NSCLC undergoing radical treatment, is the spread of distant metastases. ${ }^{55,56,59}$
In our review, we identified 7 articles analyzing SABR in patients with NSCLC oligometastases. Three were prospective studies and 4 retrospective analyses. Overall, 737 patients were included. The details are described in Table 3.

In our analysis, LC rates after SABR ranged from $84.32 \%$ to $91.9 \%$ at 1 year. OS rates ranged from $67 \%$ to $81.5 \%$ at 1 year. The 2 -year OS rate was from $38 \%$ to $80.8 \%$. PFS ranged from $33.3 \%$ to $45 \%$ at 1 year and from $8 \%$ to $22 \%$ after 2 years.

Surely, the number of metastases turns out to be a determining factor. In 2012, Salama et al presented the results of a dose escalation study (SABR). In analysis, they evaluated 61 patients with one to five metastases (total: 113 metastatic lesions) but only 11 patients with stage IV NSCLC. We have the survival outcomes of the entire population of patients and not of NSCLC subgroup. The median follow-up was 20.9 months. Treatment was well tolerated. At 2 years, the PFS and OS rates were $22 \%$ and $56.7 \%$, respectively. After SABR, the $72 \%$ of patients had a further oligoprogression with a better 2-year OS for patients with 1-3 metastases compared to patients with 45 metastases. ${ }^{57}$ In their systematic review and pooled analysis of the literature, Ashworth et al included 49 studies that analyzed 2176 oligometastatic NSCLC patients with up to 5 lesions and treated with surgery or radiotherapy. The $83 \%$ of patients, at the time of treatment, had controlled thoracic disease. About $53 \%$ of studies focused on patients with single metastasis, and $60 \%$ of studies included patients with brain metastases only. The median survival was 13.8 months, median PFS was 12 months, and the 5 -year survival was $23 \%$. The prognostic factors were the control of the primary tumor, the thoracic lymph nodes stage, and disease-free interval of more than 12 months (6 months for adrenal metastases) prior to oligometastatic presentation. ${ }^{58} \mathrm{~A}$ meta-analysis of individual patient data by Ashworth and colleagues included 757 patients with stage IV NSCLC with 1 to 5 synchronous (76\%) and metachronous (24\%) metastases treated with ablative therapies (metastasectomy, SABR or stereotactic radiosurgery or radical external beam radiotherapy and curative intent treatment of the primary chest disease). Median survival was 26 months, and the median PFS was 11 months. The OS at 5 and 8 years the rates were $29 \%$ and $23 \%$, respectively. The analysis was performed stratifying the patients into low (metachronous metastasis; 5 -year survival, $48 \%$ ), intermediate (synchronous metastasis, no thoracic metastatic lymph nodes; 5-year survival, 


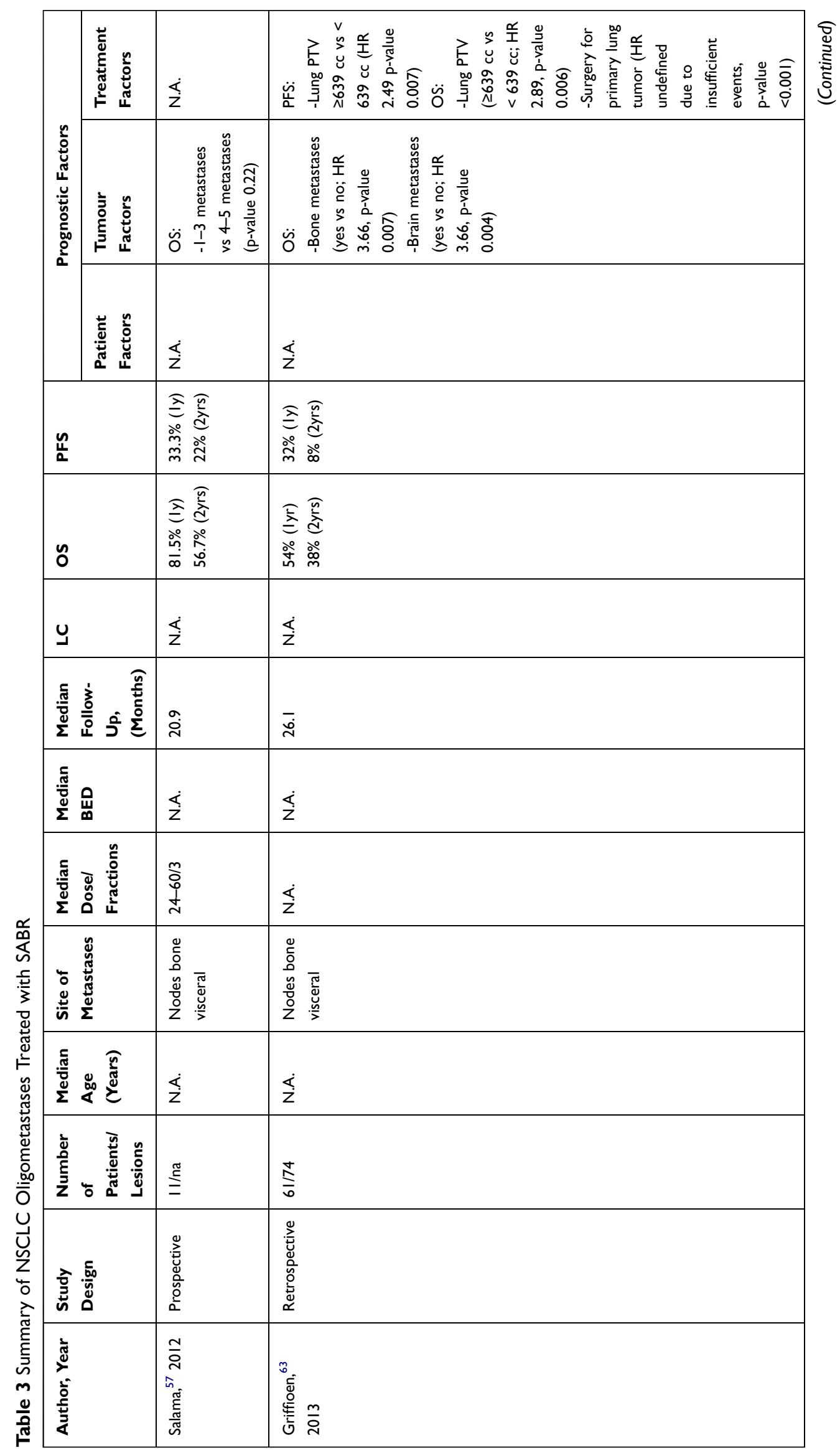




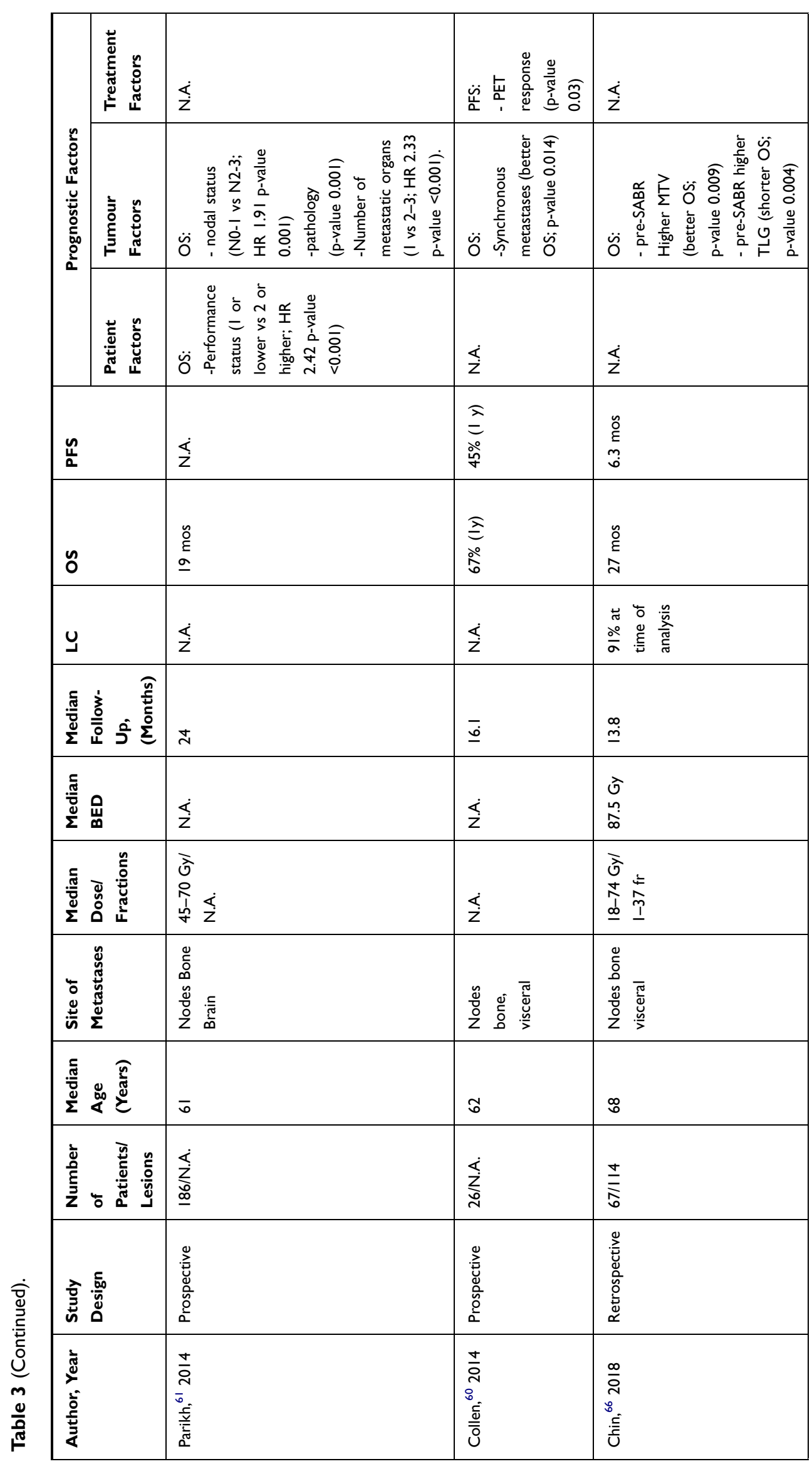




\begin{tabular}{|c|c|}
\hline$\overleftarrow{z}$ & 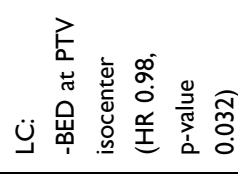 \\
\hline 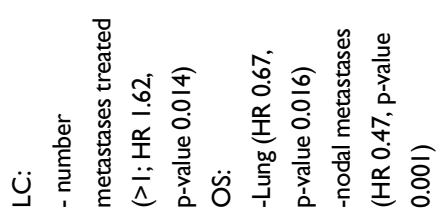 & 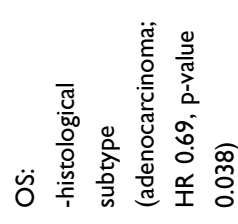 \\
\hline 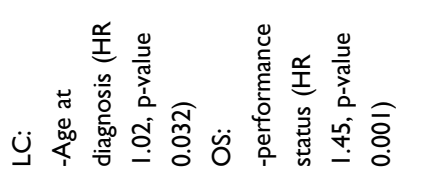 & 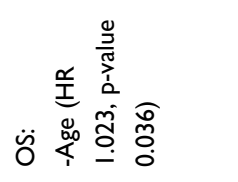 \\
\hline 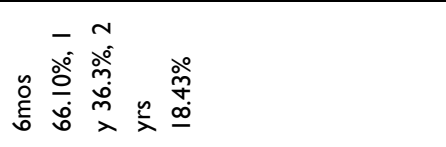 & ¿̇ \\
\hline 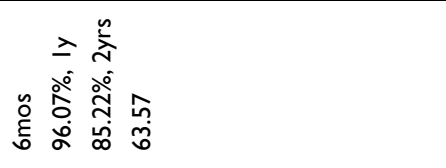 & 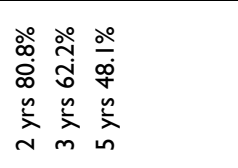 \\
\hline 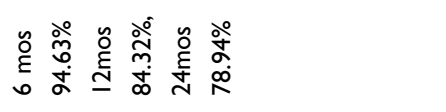 & 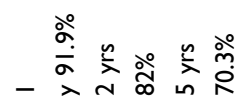 \\
\hline$\frac{\infty}{m}$ & $\bar{\omega}$ \\
\hline 으 & $\check{z}$ \\
\hline 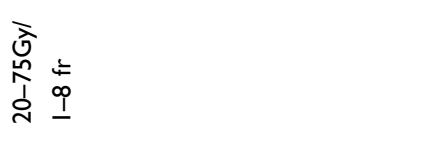 & 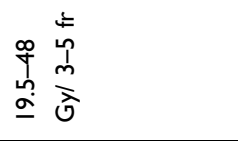 \\
\hline 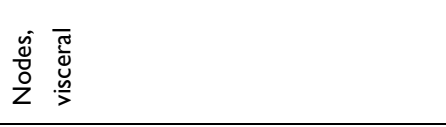 & 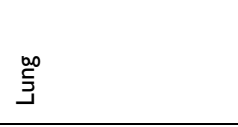 \\
\hline$\stackrel{\circ}{\tilde{\beta}}$ & $\begin{array}{l}\text { Ln } \\
0 \\
0\end{array}$ \\
\hline 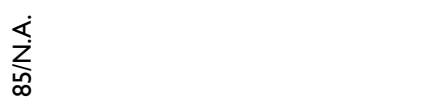 & 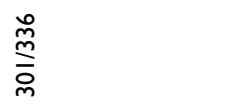 \\
\hline 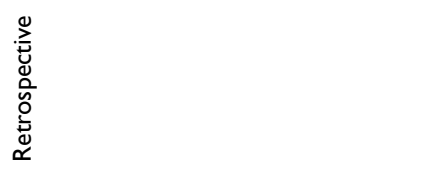 & 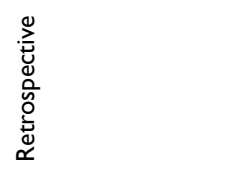 \\
\hline 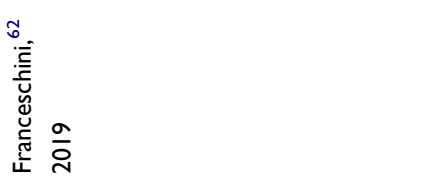 & 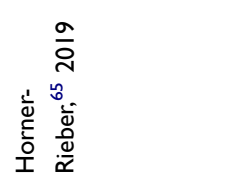 \\
\hline
\end{tabular}


$36 \%$ ) and high-risk disease (synchronous, thoracic metastatic lymph nodes; 5-year survival, 14\%), and better survival was observed in oligometastatic patients with metachronous oligometastases. ${ }^{59}$

On the contrary, in the prospective study by Collen et al, patients with synchronous presentation of metastases were associated with better OS. ${ }^{60}$

The performance status (PS) of the metastatic patient plays a predominant role. In a retrospective study, Parikh et al demonstrated that patients with Eastern Cooperative Oncology Group (ECOG) PS $>2$, with squamous cell histology and with multiple organ metastases, had an increased risk of death. Instead, the definitive treatment of the primary cancer may confer a survival benefit. ${ }^{61}$ One of the predictors of response to SABR is certainly also the site of metastases.

In a retrospective analysis, Franceschini et al evaluated a possible correlation between the characteristics of patients undergoing radiotherapy treatments with the response to SABR and survival. They included 358 patients with oligometastatic disease $(23,7 \%$ with NSCLC). Median follow-up was 31.8 months. LC and PFS at 24 months were, respectively, $78.9 \%$ and $18.4 \%$, and the OS at 24 months was $63.5 \%$. On the multivariate analysis, a better OS was reached in patients with pulmonary and nodal metastases. But the primary lung cancer, older age and the presence of metastatic sites other than the irradiated were all independent predictors of shorter OS. ${ }^{62}$ Griffioen et al conducted a retrospective analysis of patients with synchronous oligometastases treated with radical intent at all disease sites and found a correlation between survival and site of metastasis at initial presentation. Notably, survival was better in patients with brain metastases than in those with bone metastases. In addition, other prognostic factors correlated with better survival were primary tumor surgery and smaller radiotherapy planning target volume. ${ }^{63}$

$\mathrm{Li}$ et al, in their meta-analysis, analyzed 24 studies to find prognostic factors in oligometastatic NSCLC. They included 1935 patients. Female sex, (y)pN0 stage and adenocarcinoma histology were significant prognostic factors for survival in the univariate analysis. In the multivariate analysis, (y)pN0 was associated with better OS when compared with disease at the (y)pN1 stage, but not at the (y)pN2 stage. Furthermore, patients receiving radical treatments on the primary tumor or on oligometastases had better OS. ${ }^{64}$ The correlation between OS and histological subtype was also found in the retrospective study by
Hörner-Rieber et al on 301 patients with oligometastatic NSCLC. ${ }^{65}$

The use of FDG PET could give useful information on the response to radiotherapy treatment.

Chin et al, in a retrospective cohort study, analyzed 67 radiotherapy-treatment courses in 55 patients with oligometastatic NSCLC. They evaluated the metabolic tumor volume (MTV), total lesion glycolysis (TLG) and $\mathrm{SUV}_{\max }$ of all lesions on pretreatment FDG-PET. In the univariate and multivariate analysis, high MTV and TLG were predictors for shorter OS. ${ }^{66}$ Moreover, in the study by Collen et al a FDG PET response was positively correlated with better PFS. ${ }^{60}$

Lastly, the molecular profile seems to have an important prognostic role. In a single-center study published by Lussier et al, the expression of MicroRNAs (miRNAs) of lung lesions was analyzed in 63 oligometastatic patients undergoing radical curative treatment. Patients were then distinguished by relapse rate. The authors demonstrated that each different subset of patients expressed specific miRNAs, finding a profile able to predict response and prognosis of oligometastatic patient. ${ }^{67}$

\section{Breast Cancer}

Metastatic breast cancer is defined as an incurable disease. ${ }^{68}$ Historically, the role of systemic therapies has been predominant, while local radiotherapy was limited to a palliative setting. ${ }^{69,70}$ Primarily, breast cancer-related mortality is attributed to complications related to distant recurrence or metastasis. Approximately $6 \%$ of breast cancer cases are reported to have metastases at diagnosis and approximately $20-30 \%$ of early-stage breast cancers develop distant metastases. ${ }^{71}$ In recent years, the use of local therapies for oligometastatic disease has undergone a rapid increase. From a recent survey, with more than 1000 radiotherapists, it emerged that about $60 \%$ of participants use ablative radiotherapy treatment if the patient has a limited number of metastases ${ }^{72}$ and a similar result was also found in the case of surgical choice. ${ }^{73}$

However, the metastatic breast cancer population has significant variability depending on various factors. In fact, from the clinical trials carried out, the overall results can be influenced by various characteristics, such as age, PS, hormonal status, the stage of disease at diagnosis, the execution of adjuvant chemotherapy or the response to systemic treatments. ${ }^{74}$

In our review, we identified 8 articles analyzing SABR in patients with breast cancer oligometastases. Four were 
prospective studies and 4 retrospective analyses. Overall, 323 patients were included. The details are described in Table 4.

According to our analysis, LC rates after SABR ranged from $92.2 \%$ to $100 \%$ at 1 year and from $69.6 \%$ to $90 \%$ after 2 years. OS rates ranged from $85.2 \%$ to $100 \%$ at 1 year. The 2-year OS rate ranged from $57 \%$ to $100 \%$. PFS ranged from $38.7 \%$ to $75 \%$ at 1 year and from $16.6 \%$ to $65 \%$ after 2 years.

The number of lesions is a fundamental criterion for defining the response to ablative radiotherapy treatments. A correlation between the number of lesions and survival was evaluated in some studies. In Milano et al, patients with a single metastasis (vs $>1$ ) were found to have better OS. $^{75}$ In the retrospective study by Yoo et al, in which 50 patients were treated with radiotherapy at oligometastatic sites, an association with better OS was found in patients with a single bone metastasis. ${ }^{76}$ In Franzese et al, in a retrospective analysis of 72 patients treated with ablative radiotherapy on liver metastases (1-5 metastases), the number of treated liver lesions in the univariate analysis predicted worse control of liver disease ( 1 metastasis vs $>1$ metastasis). ${ }^{77}$ Also, in the retrospective study by Weykamp et al, in which 46 patients treated with SABR were analysed, the presence of a solitary metastasis was an independent prognostic factor for better disease control and PFS in multivariate analysis. ${ }^{78}$ Also, the localization of the lesions becomes a fundamental parameter for predicting survival. In a prospective observational study by Scorsetti et al, SABR was used in patients with oligometastatic breast cancer, affected by liver and lung metastases. Among the inclusion criteria, the presence of stable extrapulmonary or extrahepatic disease was allowed and it correlated with worse PFS as found by the authors. In the univariate analysis, they also demonstrated a correlation between disease free interval $>12$ months and better survival. ${ }^{79}$ An advantage in OS was found in the study of Milano et al, in which patients with bone disease had better OS than patients who also had other sites of disease. ${ }^{75}$ The table shows how the OS at 2 years differs between the different studies, and the lowest survival was found in the study by Onal et al (2-years OS 57\%), which retrospectively analyzed patients with liver metastases undergoing SABR. ${ }^{80}$ In Yoo et al retrospective analysis, a correlation was found between high RT $(\geq 50$ Gy10) and increased LC and better distant-PFS. ${ }^{76}$ In a study performed using a large multi-center database from German society of radiation Oncology, Klement et al show that breast cancer metastases treated with $\mathrm{SABR}$ (with $\mathrm{BED}_{\max }$ of $157 \pm 80 \mathrm{~Gy}_{10}$ or $80 \pm 62 \mathrm{~Gy}_{10}$ with and without prior chemotherapy) have a significantly higher probability of tumor control over the entire doseresponse, and this shows that this subtype could be particularly radiosensitive to high doses per fraction such as in SABR ${ }^{81}$ Furthermore, the pooled analysis by Hong et al, which also included patients with oligometastatic breast cancer, also showed a correlation between BED >75 Gy and better OS and PFS. ${ }^{82}$

The biomolecular factors of breast disease also predict a different response to radiotherapy treatments.

In our analysis, we found various studies showing these predictors. Hormone receptor positivity of patients undergoing SABR was found to be linked to improved OS in 3 of the studies included in our analysis. ${ }^{75,76,79}$ A worse survival was instead demonstrated by Franzese et al for the patients who presented a HER-2 positivity. $^{77}$ It is also very important to note that the Karnofsky Performance Status Scale was a significant positive prognostic factor for survival and disease control. Indeed, some studies included high KPS as an inclusion criterion with a range between $70 \%$ $100 \%{ }^{75,78,83}$ The timing of systemic medical treatment was evaluated by Scorsetti et al, who demonstrated a significant impact on OS in case of systemic treatment after SABR. ${ }^{79}$ In the study by Franzese et al, a correlation was found between systemic therapy administered before local treatment on metastases and PFS. ${ }^{77}$ We also found interesting data from a prospective study. In a phase II study, published by Trovò et al, the authors sought to demonstrate whether radical radiotherapy on all metastatic sites could increase PFS in patients with oligometastatic breast cancer. They included 54 patients with a total of 92 metastatic lesions, treated with radical radiotherapy, in their analysis. After a median follow-up of 30 months, the PFS at 1 and 2 years was $75 \%$ and $53 \%$, respectively. They did not identify prognostic factors associated with improvement in PFS. However, they showed that patients treated with radical radiotherapy on all metastatic sites may reach long-term PFS without significant treatment-related toxicity increase. Therefore, the choice of stereotactic ablative radiotherapy can be considered a valid option. ${ }^{84}$

\section{Conclusion}

Through this review, we provide a state of the art summary of predictive factors that can help deciding whether oligometastatic patients deserve SABR. It is evident that a lot is still to be done, as reflected by the various and heterogeneous results 


\begin{tabular}{|c|c|c|c|c|}
\hline 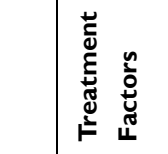 & 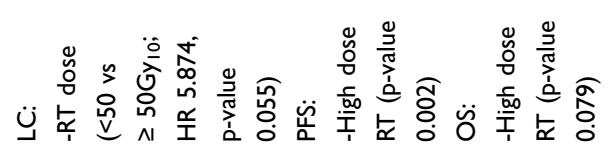 & 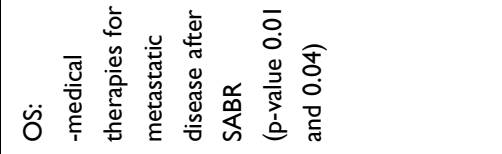 & ¿̇ & ¿̇ \\
\hline 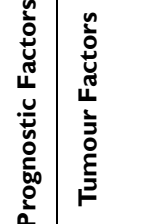 & 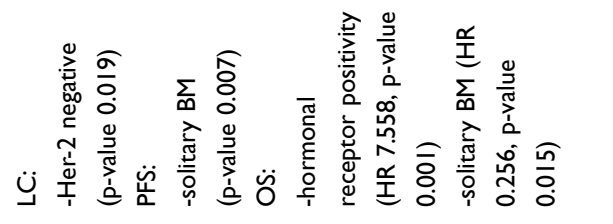 & 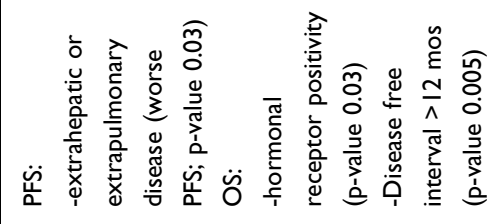 & $\dot{¿}$ & $\overleftarrow{\Sigma}$ \\
\hline 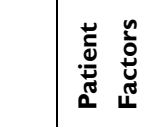 & 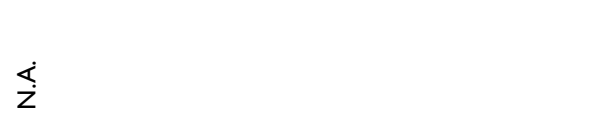 & ¿্র & $\overleftarrow{z}$ & $\overleftarrow{z}$ \\
\hline$\frac{n}{2}$ & 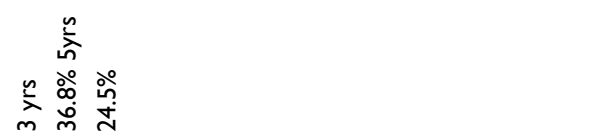 & 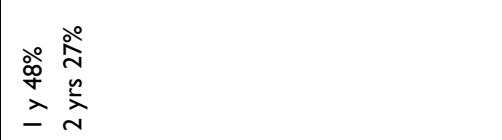 & 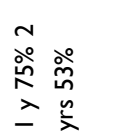 & $\check{Z}$ \\
\hline ถั & 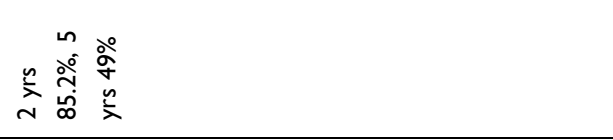 & 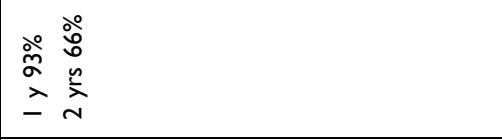 & 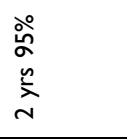 & 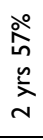 \\
\hline U & 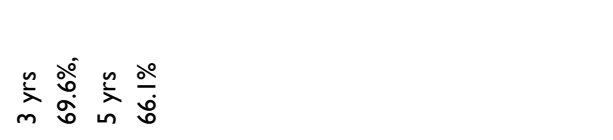 & 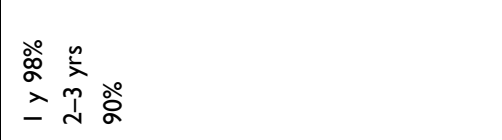 & 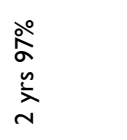 & 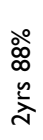 \\
\hline 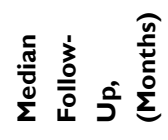 & $\stackrel{\text { ஸ் }}{\text { ஸे }}$ & 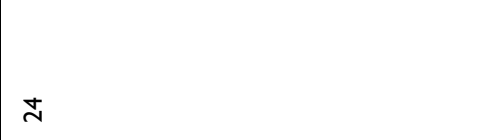 & ஓ & $\underline{0}$ \\
\hline 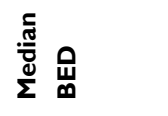 & 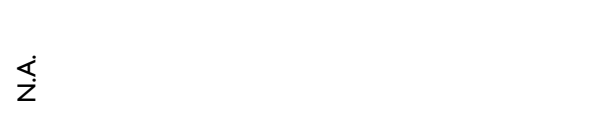 & 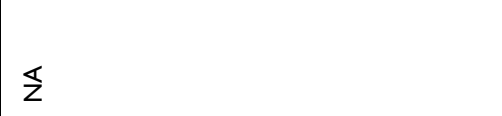 & 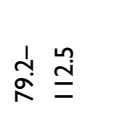 & ¿̇ \\
\hline 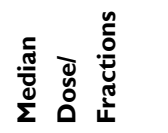 & 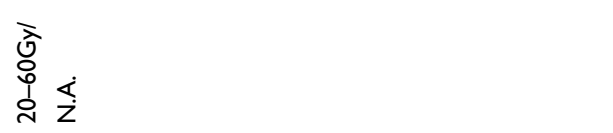 & 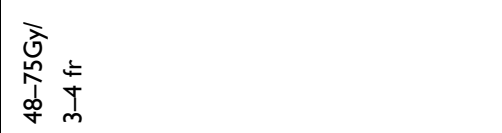 & 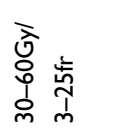 & 忘 \\
\hline 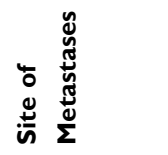 & 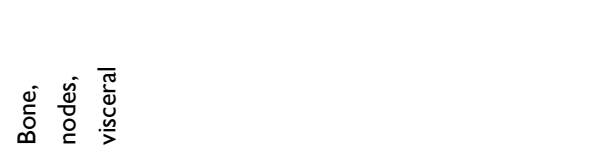 & 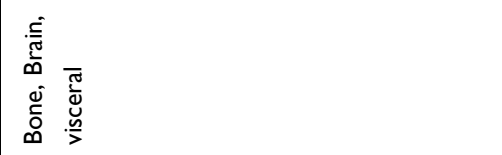 & 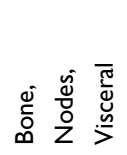 & 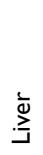 \\
\hline 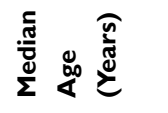 & $\mathscr{f}$ & in & 㶽 & f \\
\hline 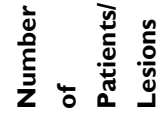 & 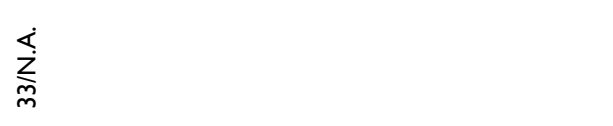 & 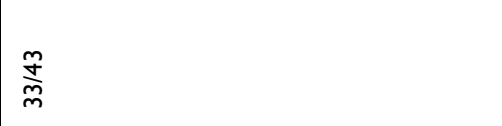 & 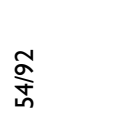 & ָิ \\
\hline 窟离 & 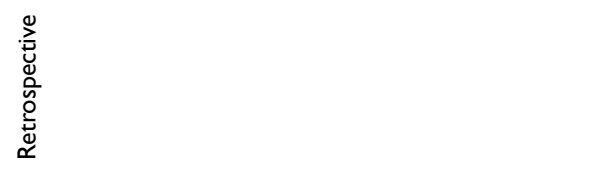 & 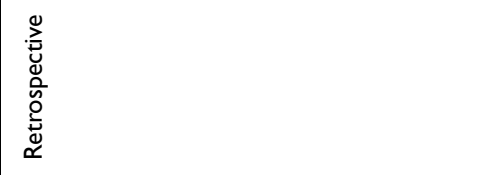 & 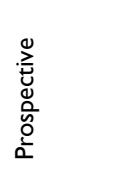 & 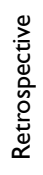 \\
\hline 咅市 & $\begin{array}{l}\frac{\ln }{2} \\
\stackrel{2}{2} \\
\stackrel{0}{\circ} \\
\stackrel{0}{\succ}\end{array}$ & 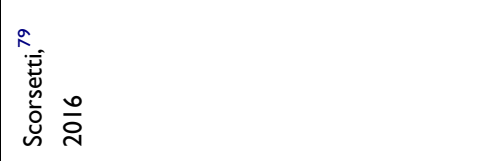 & 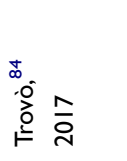 & 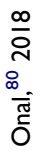 \\
\hline
\end{tabular}




\begin{tabular}{|c|c|c|}
\hline$\stackrel{\Delta}{Z}$ & 这 & 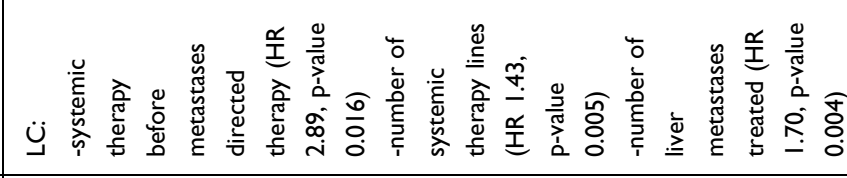 \\
\hline 这 & 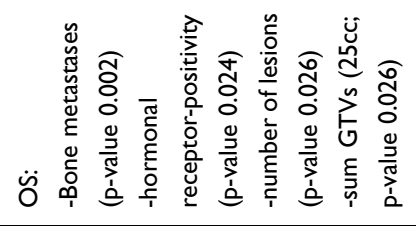 & 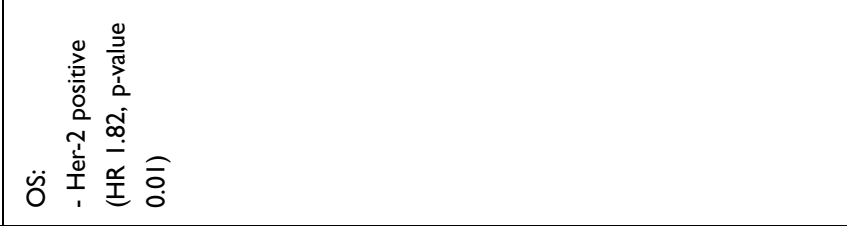 \\
\hline$\overleftarrow{Z}$ & $\underset{i}{Z}$ & 这 \\
\hline 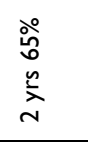 & 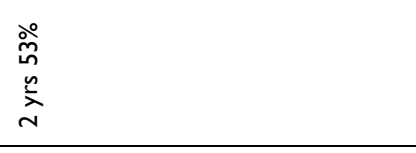 & 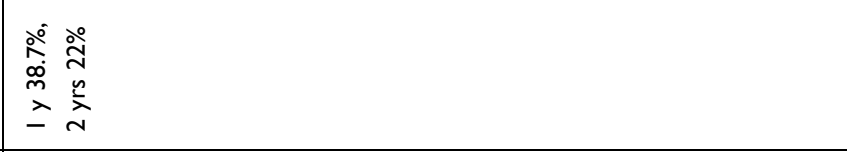 \\
\hline$\frac{\stackrel{\circ}{0}}{\frac{\delta}{\grave{n}}}$ & 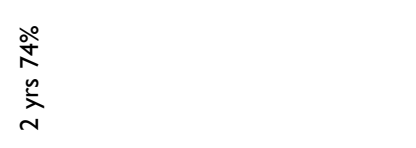 & 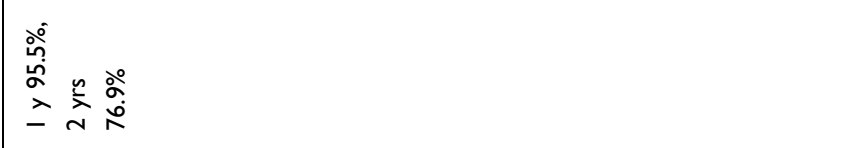 \\
\hline 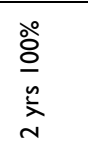 & 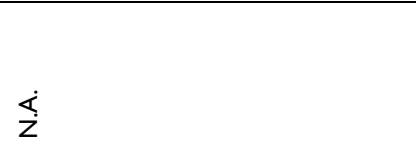 & $\overleftrightarrow{Z}$ \\
\hline$\stackrel{ \pm}{\sim}$ & $\tilde{n}$ & ָ̊. \\
\hline$\stackrel{\dot{X}}{\mathrm{Z}}$ & $\stackrel{\check{L}}{\mathrm{z}}$ & 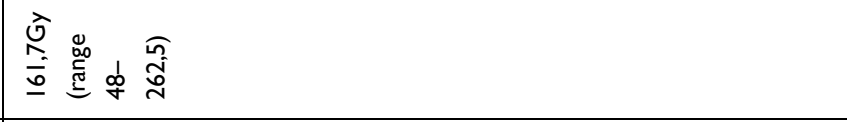 \\
\hline 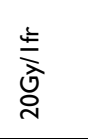 & 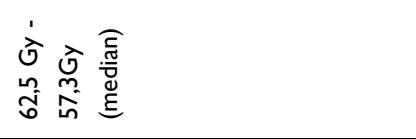 & 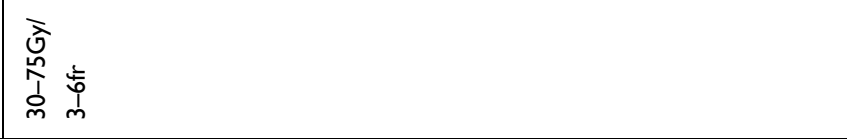 \\
\hline $\begin{array}{l}0 \\
\stackrel{0}{0} \\
\infty\end{array}$ & 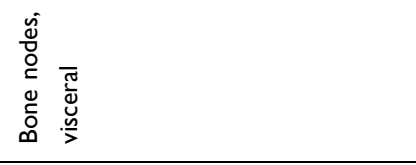 & $\stackrel{\bar{\nu}}{\beth}$ \\
\hline$\overline{0}$ & $\begin{array}{l}\alpha \\
\dot{q} \\
\dot{c} \\
\dot{0}\end{array}$ & 葍 \\
\hline$\frac{9}{\sqrt[3]{3}}$ & 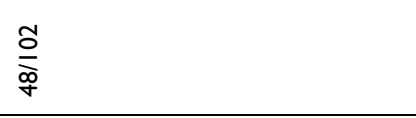 & 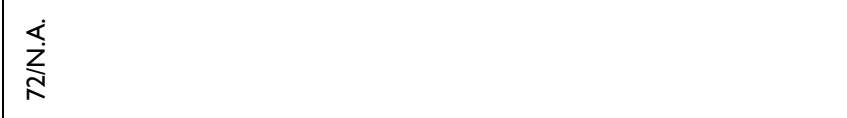 \\
\hline 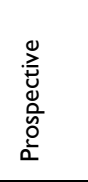 & 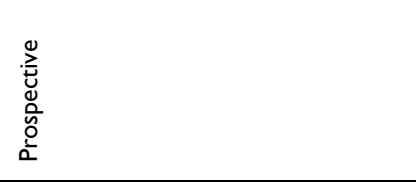 & 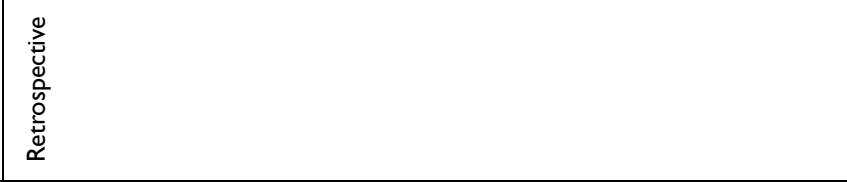 \\
\hline 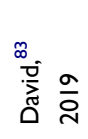 & 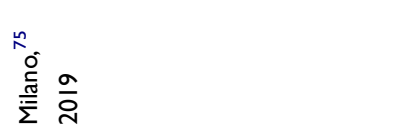 & 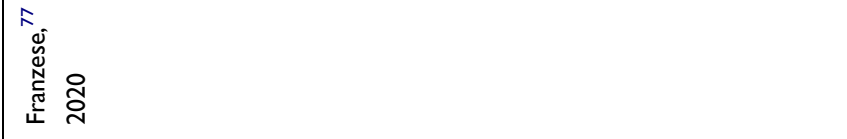 \\
\hline
\end{tabular}


$\underline{\text { Franceschini et al }}$

Dovepress

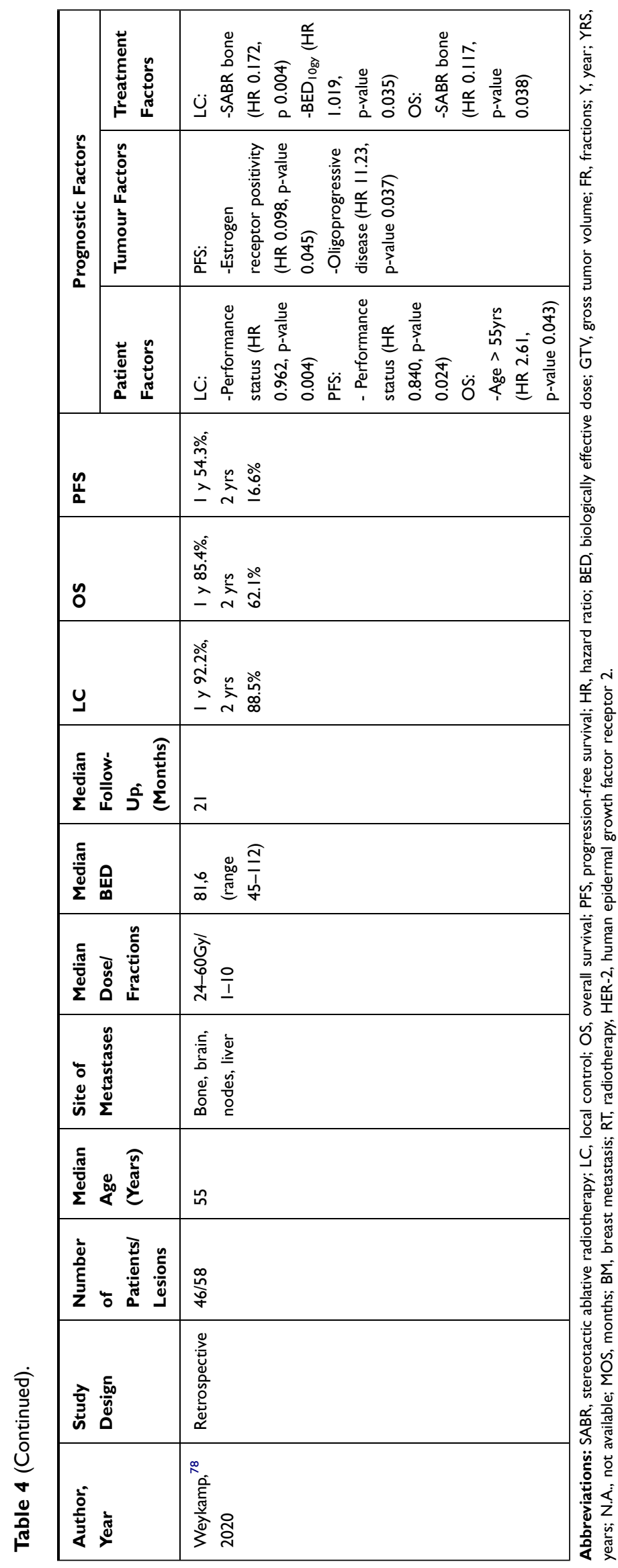

$\mathbf{7 0 2 8}$ https://doi.org// 0.21 47/CMAR.S2941।6

Cancer Management and Research 2021:13 
of the published series. While clinical parameters are easily accessible, their relevance in predicting outcome of oligometastatic patients is minimal. The research on genetic, epigenetic and radiomic features is still far from a clinical implementation. However, we feel that this is the right way to proceed, since the identification of the biology behind oligometastases is crucial. A significant effort to collect similar data is of paramount importance.

\section{Disclosure}

The authors report no conflicts of interest in this work.

\section{References}

1. Hellman S, Weichselbaum R. Oligometastases. J Clin Oncol. 1995;13 (1):8-10. doi:10.1200/JCO.1995.13.1.8

2. Barney J, Churchill E. Adenocarcinoma of the kidney with metastasis to the lung cured by nephrectomy and lobectomy. $J$ Urol. 1939;42 (3):269-276. doi:10.1016/S0022-5347(17)71516-9

3. Guckenberger M, Lievens Y, Bouma AB, et al. Characterisation and classification of oligometastatic disease: a European society for radiotherapy and oncology and European organisation for research and treatment of cancer consensus recommendation. Lancet Oncol. 2020;21(1):e18-e28. doi:10.1016/S1470-2045(19)30718-1

4. Palma DA, Olson R, Harrow S, et al. Stereotactic ablative radiotherapy versus standard of care palliative treatment in patients with oligometastatic cancers (sabr-comet): a randomised, phase 2, open-label trial. Lancet. 2019;393(10185):2051-2058. doi:10.1016/ S0140-6736(18)32487-5

5. Gomez DR, Tang C, Zhang J, et al. Local consolidative therapy vs maintenance therapy or observation for patients with oligometastatic non small-cell lung cancer: long-term results of a multi-institutional, Phase II, randomized study. J Clin Oncol. 2019;37(18):1558-1565. doi:10.1200/JCO.19.00201

6. Ost P, Reynders D, Decaestecker K, et al. Surveillance or metastasis directed therapy for oligometastatic prostate cancer recurrence: a prospective, randomized, multicenter phase II trial. J Clin Oncol. 2018;36(5):446-453

7. Iyengar P, Wardak Z, Gerber DE, et al. Consolidative radiotherapy for limited metastatic non-small-cell lung cancer: a phase 2 randomized clinical trial. JAMA Oncol. 2018;4(1):e173501-e173501. doi:10.1001/jamaoncol.2017.3501

8. Galandiuk S, Wieand HS, Moertel CG, et al. Patterns of recurrence after curative resection of carcinoma of the colon and rectum. Surg Gynecol Obstet. 1992;174:27-32.

9. Elias D, Benizri E, Vernerey D, et al. Preoperative criteria of incomplete resectability of peritoneal carcinomatosis from non-appendiceal colorectal carcinoma. Gastroenterol Clin Biol. 2005;29(10):10 10-1013. doi:10.1016/S0399-8320(05)88175-8

10. Pfannschmidt J, Muley T, Hoffmann H, et al. Prognostic factors and survival after complete resection of pulmonary metastases from colorectal carcinoma: experiences in 167 patients. $J$ Thorac Cardiovasc Surg. 2003;126(3):732-739. doi:10.1016/S0022-5223(03)00587-7

11. Yedibela S, Klein P, Feuchter K, et al. Surgical management of pulmonary metastases from colorectal cancer in 153 patients. Ann Surg Oncol. 2006;13(11):1538-1544. doi:10.1245/s10434-006-9100-2

12. Fernandez FG, Drebin JA, Linehan DC, et al. Five-year survival after resection of hepatic metastases from colorectal cancer in patients screened by positron emission tomography with F-18 fluorodeoxyglucose (FDG-PET). Ann Surg. 2004;240(3):438-447 discussion $447-50$.
13. Pawlik TM, Scoggins CR, Zorzi D, et al. Effect of surgical margin status on survival and site of recurrence after hepatic resection for colorectal metastases. Ann Surg. 2005;241(5):715-722 discussion 722-4. doi:10.1097/01.sla.0000160703.75808.7d

14. Kobiela J, Spychalski P, Marvaso G, et al. Ablative stereotactic radiotherapy for oligometastatic colorectal cancer: systematic review. Crit Rev Oncol Hematol. 2018;129:91-101. doi:10.1016/j. critrevonc.2018.06.005.

15. Choi HS, Jeong BK, Mun Kang K, et al. Tumor control and overall survival after stereotactic body radiotherapy for pulmonary oligometastases from colorectal cancer: a meta-analysis. Cancer Res Treat. 2020;52(4):1188-1198. doi:10.4143/crt.2020.402.

16. Li S, Don D, Geng J, et al. Prognostic factors and optimal response interval for stereotactic body radiotherapy in patients with lung oligometastases or oligoprogression from colorectal cancer. Front Oncol. 2019;9:1080. doi:10.3389/fonc.2019.01080.;.

17. Jingu K, Matsuo Y, Onishi H, et al. Dose escalation improves outcome in stereotactic body radiotherapy for pulmonary oligometastases from colorectal cancer. Anticancer Res. 2017;37(5):2709-2713. doi:10.21873/anticanres.11621.

18. Joo JH, Park J, Kim JC, et al. Local control outcomes using stereotactic body radiation therapy for liver metastases from colorectal cancer. Int J Radiat Oncol Biol Phys. 2017;99(4):876-883. doi:10.1016/j.ijrobp.2017.07.030.

19. Thompson R, Cheung P, Chu W, et al. Outcomes of extra-cranial stereotactic body radiotherapy for metastatic colorectal cancer: dose and site of metastases matter. Radiother Oncol. 2020;142:236-245. doi:10.1016/j.radonc.2019.08.018.

20. Yu J, Li N, Tang Y, et al. Outcomes after hypofractionated stereotactic radiotherapy for colorectal cancer oligometastases. J Surg Oncol. 2019;119(4):532-538. doi:10.1002/jso.25361.

21. Dell'Acqua V, Surgo A, Kraja F, et al. Stereotactic radiation therapy in oligometastatic colorectal cancer: outcome of 102 patients and 150 lesions. Clin Exp Metastasis. 2019;36(4):331-342. doi:10.1007/ s10585-019-09976-z.

22. Sharma A, Baker S, Duijm M, et al. Prognostic factors for local control and survival for inoperable pulmonary colorectal oligometastases treated with stereotactic body radiotherapy. Radiother Oncol. 2020;144:23-29. doi:10.1016/j.radonc.2019.10.004.

23. Comito T, Cozzi L, Clerici E, et al. Stereotactic Ablative Radiotherapy (SABR) in inoperable oligometastatic disease from colorectal cancer: a safe and effective approach. BMC Cancer. 2014;14(1):619. doi:10.1186/1471-2407-14-619.

24. Bae SH, Kim MS, Cho CK, et al. High dose stereotactic body radiotherapy using three fractions for colorectal oligometastases. $J$ Surg Oncol. 2012;106(2):138-143. doi:10.1002/jso.23058.

25. Kang JK, Kim MS, Kim JH, et al. Oligometastases confined one organ from colorectal cancer treated by SBRT. Clin Exp Metastasis. 2010;27(4):273-278. doi:10.1007/s10585-010-9325-0.

26. Jethwa KR, Jang S, Mullikin TC, et al. Association of tumor genomic factors and efficacy for metastasis-directed stereotactic body radiotherapy for oligometastatic colorectal cancer. Radiother Oncol. 2020;146:29-36. doi:10.1016/j.radonc.2020.02.008.

27. Franzese C, Comito T, Toska E, et al. Predictive factors for survival of oligometastatic colorectal cancer treated with Stereotactic body radiation therapy. Radiother Oncol. 2019;133:220-226. doi:10.1016/ j.radonc.2018.10.024.

28. Ji X, Zhao Y, Zhu X, et al. Outcomes of stereotactic body radiotherapy for metastatic colorectal cancer with oligometastases, oligoprogression, or local control of dominant tumors. Front Oncol. 2021;10:595781. doi:10.3389/fonc.2020.595781.

29. Ottaiano A, Scotti V, De Divitiis C, et al. Integration of stereotactic radiotherapy in the treatment of metastatic colorectal cancer patients: a real practice study with long-term outcome and prognostic factors. Oncotarget. 2018;9(81):35251-35265. doi:10.18632/oncotarget.25 834. 
30. Hoyer M, Roed H, Traberg Hansen A, et al. Phase II study on stereotactic body radiotherapy of colorectal metastases. Acta Oncol. 2006;45(7):823-830. doi:10.1080/02841860600904854.

31. Pitroda SP, Khodarev NN, Huang L, et al. Integrated molecular subtyping defines a curable oligometastatic state in colorectal liver metastasis. Nat Commun. 2018;9(1):20.

32. Narayan RR, Goldman DA, Gonen M, et al. Peripheral circulating tumor DNA detection predicts poor outcomes after liver resection for metastatic colorectal cancer. Ann Surg Oncol. 2019;26:1824-1832.

33. Tsilimigras DI, Ntanasis-Stathopoulos I, Bagante F, et al. Clinical significance and prognostic relevance of KRAS, BRAF, PI3K and TP53 genetic mutation analysis for resectable and unresectable colorectal liver metastases: a systematic review of the current evidence. Surg Oncol. 2018;27(2):280-288. doi:10.1016/j.suronc.2018.05.012

34. Nicosia L, Cuccia F, Mazzola R, et al. Disease course of lung oligometastatic colorectal cancer treated with stereotactic body radiotherapy. Strahlenther Onkol. 2020;196(9):813-820. doi:10.10 07/s00066-020-01627-7.

35. Cornford P, Bellmunt J, Bolla M, et al. EAU-ESTRO-SIOG guidelines on prostate cancer. Part II: treatment of relapsing, metastatic, and castration-resistant prostate cancer. Eur Urol. 2017;71 (4):630-642. doi:10.1016/j.eururo.2016.08.002

36. Fakhrejahani F, Madan RA, Dahut WL. Management options for biochemically recurrent prostate cancer. Curr Treat Options Oncol. 2017;18(5):26. doi:10.1007/s11864-017-0462-4

37. Kyriakopoulos CE, Chen YH, Carducci MA, et al. Chemohormonal therapy in metastatic hormone-sensitive prostate cancer: long-term survival analysis of the randomized phase III E3805 CHAARTED trial. J Clin Oncol. 2018;36(11):1080-1087. doi:10.1200/JCO.2017. 75.3657

38. Fizazi K, Tran NP, Fein L, et al. Abiraterone acetate plus prednisone in patients with newly diagnosed high-risk metastatic castration-sensitive prostate cancer (LATITUDE): final overall survival analysis of a randomised, double-blind, Phase 3 trial. Lancet Oncol. 2019;20(5):686-700. doi:10.1016/S1470-2045(19)30082-8.

39. Ost P, Bossi A, Decaestecker K, et al. Metastasis- directed therapy of regional and distant recurrences after curative treatment of prostate cancer: a systematic review of the literature. Eur Urol. 2015;67 (5):852-863. doi:10.1016/j.eururo.2014.09.004

40. Kothari G, Ost P, Cheung P, et al. Trends in management of oligometastatic hormone-sensitive prostate cancer. Curr Oncol Rep. 2019;21(5):43. doi:10.1007/s11912-019-0791-5.

41. Niazi T, Elakshar S, Stroian G. Local ablative stereotactic body radiotherapy for oligometastatic prostate cancer. Curr Opin Support Palliat Care. 2018;12(3):351-358. doi:10.1097/SPC.00000000000 00371.

42. Schick U, Jorcano S, Nouet $\mathrm{P}$, et al. Androgen deprivation and high-dose radiotherapy for oligometastatic prostate cancer patients with less than five regional and/or distant metastases. Acta Oncol. 2013;52(8):1622-1628. doi:10.3109/0284186X.2013.764010.

43. Bowden P, See AW, Frydenberg M, et al. Fractionated stereotactic body radiotherapy for up to five prostate cancer oligometastases: interim outcomes of a prospective clinical trial. Int $J$ Cancer. 2020;146(1):161-168. doi:10.1002/ijc.32509.

44. Ost P, Jereczek-Fossa BA, Van As N, et al. Progression-free survival following stereotactic body radiotherapy for oligometastatic prostate cancer treatment-naive recurrence: a multi-institutional analysis. Eur Urol. 2016;69(1):9-12. doi:10.1016/j.eururo.2015.07.004.

45. Franzese C, Zucali PA, Di Brina L, et al. The efficacy of Stereotactic body radiation therapy and the impact of systemic treatments in oligometastatic patients from prostate cancer. CancerMed. 2018;7 (9):4379-4386. doi:10.1002/cam4.1707.

46. Triggiani L, Mazzola R, Magrini SM, et al. Metastasis-directed stereotactic radiotherapy for oligoprogressive castration-resistant prostate cancer: a multicenter study. World J Urol. 2019;37 (12):2631-2637. doi:10.1007/s00345-019-02717-7.
47. Hurmuz P, Onal C, Ozyigit G, et al. Treatment outcomes of metastasis-directed treatment using 68Ga-PSMA-PET/CT for oligometastatic or oligorecurrent prostate cancer: Turkish Society for Radiation Oncology group study (TROD 09-002). Strahlenther Onkol. 2020;196(11):1034-1043. doi:10.1007/ s00066-020-01660-6.

48. Jereczek-Fossa BA, Fanetti G, Fodor C, et al. Salvage stereotactic body radiotherapy for isolated lymph node recurrent prostate cancer: single institution series of 94 consecutive patients and 124 lymph nodes. Clin Genitourin Cancer. 2017;15(4):e623-e632. doi:10.1016/ j.clgc.2017.01.004.

49. Franzese C, Di Brina L, D’Agostino G, et al. Predictive factors for survival outcomes of oligometastatic prostate cancer patients treated with metastases-directed therapy: a recursive partitioning-based analysis. J Cancer Res Clin Oncol. 2019;145(10):2469-2479. doi:10.10 07/s00432-019-03007-w.

50. Lorenzo Livi. Phase II randomized trial of radiation therapy in oligometastatic mCRPC prostate cancer (ARTO).

51. Francolini G, Garlatti P, Loi M, et al. ARTO trial (NCT03449719), a randomized phase II trial enrolling oligometastatic castration-resistant prostate cancer patients treated with first-line abiraterone acetate with or without stereotactic body radiation therapy: preliminary results comprehensive of biochemical outcomes and circulating tumor cells analysis. Journal of Clinical Oncology. 2021;39(6_suppl):118.

52. van Dessel LF, Martens JWM, Lolkema MP. Fundamentals of liquid biopsies in metastatic prostate cancer: from characterization to stratification. Curr Opin Oncol. 2020;32(5):527-534. doi:10.1097/ CCO.0000000000000655.

53. Bjerre MT, Nørgaard M, Larsen $\mathrm{OH}$, et al. Epigenetic analysis of circulating tumor DNA in localized and metastatic prostate cancer: evaluation of clinical biomarker potential. Cells. 2020;9(6):1362. doi:10.3390/cells9061362.

54. Phillips R, Shi WY, Deek M, et al. Outcomes of observation vs stereotactic ablative radiation for oligometastatic prostate cancer. The ORIOLE phase 2 randomized clinical trial. JAMA Oncol. 2020;6(5):650-659. doi:10.1001/jamaoncol.2020.0147.

55. Curran WJ Jr, Paulus R, Langer CJ, et al. Sequential vs. concurrent chemoradiation for stage III non-small cell lung cancer: randomized phase III trial RTOG 9410. J Natl Cancer Inst. 2011;103 (19):1452-1460. doi:10.1093/jnci/djr325.

56. Albain KS, Swann RS, Rusch VW, et al. Radiotherapy plus chemotherapy with or without surgical resection for stage III non-smallcell lung cancer: a phase III randomised controlled trial. Lancet. 2009;374(9687):379-386. doi:10.1016/S0140-6736(09)60737-6.

57. Salama JK, Hasselle MD, Chmura SJ, et al. Stereotactic body radiotherapy for multisite extracranial oligometastases: final report of a dose escalation trial in patients with 1 to 5 sites of metastatic disease. Cancer. 2012;118(11):2962-2970. doi:10.1002/cncr.26611.

58. Ashworth A, Rodrigues G, Boldt G, Palma D. Is there an oligometastatic state in non-small cell lung cancer? A systematic review of the literature. Lung Cancer. 2013;82(2):197-203. doi:10.1016/j. lungcan.2013.07.026.

59. Ashworth AB, Senan S, Palma DA, et al. An individual patient data metaanalysis of outcomes and prognostic factors after treatment of oligometastatic non-small-cell lung cancer. Clin Lung Cancer. 2014;15(5):346-355. doi:10.1016/j.cllc.2014.04.003.

60. Collen C, Christian N, Schallier D, et al. Phase II study of stereotactic body radiotherapy to primary tumor and metastatic locations in oligometastatic nonsmall-cell lung cancer patients. Ann Oncol. 2014;25(10):1954-1959. doi:10.1093/annonc/mdu370.

61. Parikh RB, Cronin AM, Kozono DE, et al. Definitive primary therapy in patients presenting with oligometastatic non-small cell lung cancer. Int J Radiat Oncol Biol Phys. 2014;89(4):880-887. doi:10.1016/j. ijrobp.2014.04.007. 
62. Franceschini D, De Rose F, Franzese C, et al. Predictive factors for response and survival in a cohort of oligometastatic patients treated with stereotactic body radiation therapy. Int $J$ Radiat Oncol Biol Phys. 2019;104(1):111-121. doi:10.1016/j.ijrobp.2018.12.049.

63. Griffioen GH, Toguri D, Dahele M, et al. Radical treatment of synchronous oligometastatic non-small cell lung carcinoma (NSCLC): patient outcomes and prognostic factors. Lung Cancer. 2013;82(1):95-102. doi:10.1016/j.lungcan.2013.07.023.

64. Li S, Zhu R, Li D, et al. Prognostic factors of oligometastatic non-small cell lung cancer: a meta-analysis. J Thorac Dis. 2018;10 (6):3701-3713. doi:10.21037/jtd.2018.05.105.

65. Hörner-Rieber J, Bernhardt D, Blanck O, et al. Long-term follow-up and patterns of recurrence of patients with oligometastatic NSCLC treated with pulmonary SBRT. Clin Lung Cancer. 2019;20(6):e667e677. doi:10.1016/j.cllc.2019.06.024.

66. Chin AL, Kumar KA, Guo HH, et al. Prognostic value of pretreatment FDG-PET parameters in high-dose image-guided radiotherapy for oligometastatic non-small-cell lung cancer. Clin Lung Cancer. 2018;19(5):e581-e588. doi:10.1016/j.cllc.2018.04.003.

67. Lussier YA, Khodarev NN, Regan K, et al. Oligo- and polymetastatic progression in lung metastasis(es) patients is associated with specific microRNAs. PLoS One. 2012;7(12):e50141. doi:10.1371/journal. pone.0050141.

68. Senkus E, Kyriakides S, Penault-Llorca F, et al.; ESMO Guidelines Working Group. Primary breast cancer: ESMO clinical practice guidelines for diagnosis, treatment and follow-up. Ann Oncol. 2013;24(Suppl 6):vi7-23. doi:10.1093/annonc/mdt284.

69. Reyes DK, Pienta KJ. The biology and treatment of oligometastatic cancer. Oncotarget. 2015;6(11):8491-8524. doi:10.18632/oncotarget. 3455.

70. Fisher B. Laboratory and clinical research in breast cancer-a personal adventure: the David A. Karnofsky Memorial Lecture Cancer Res. 1980;40(11):3863-3874.

71. O'Shaughnessy J. Extending survival with chemotherapy in metastatic breast cancer. Oncologist. 2005;10(Suppl 3):20-29. doi:10.16 34/theoncologist.10-90003-20.

72. Lewis SL, Porceddu S, Nakamura N, et al. Definitive Stereotactic Body Radiotherapy (SBRT) for extracranial oligometastases: an international survey of $>1000$ radiation oncologists. Am J Clin Oncol. 2017;40(4):418-422. doi:10.1097/COC.0000000000000169.

73. Bartlett EK, Simmons KD, Wachtel H, et al. The rise in metastasectomy across cancer types over the past decade. Cancer. 2015;121 (5):747-757. doi:10.1002/cncr.29134.
74. Kucharczyk MJ, Parpia S, Walker-Dilks C, et al. Ablative therapies in metastatic breast cancer: a systematic review. Breast Cancer Res Treat. 2017;164(1):13-25. doi:10.1007/s10549-017-4228-2.

75. Milano MT, Katz AW, Zhang H, et al. Oligometastatic breast cancer treated with hypofractionated stereotactic radiotherapy: some patients survive longer than a decade. Radiother Oncol. 2019;131:45-51. doi:10.1016/j.radonc.2018.11.022.

76. Yoo GS, Yu JI, Park W, et al. Prognostic factors in breast cancer with extracranial oligometastases and the appropriate role of radiation therapy. Radiat Oncol J. 2015;33(4):301-309. doi:10.3857/roj.20 15.33.4.301.

77. Franzese C, Comito T, Viganò L, et al. Liver metastases-directed therapy in the management of oligometastatic breast cancer. Clin Breast Cancer. 2020;20(6):480-486. doi:10.1016/j.clbc.2020.05.006.

78. Weykamp F, König L, Seidensaal K, et al. Extracranial stereotactic body radiotherapy in oligometastatic or oligoprogressive breast cancer. Front Oncol. 2020;10:987. doi:10.3389/fonc.2020.00987.

79. Scorsetti M, Franceschini D, De Rose F, et al. Stereotactic body radiation therapy: a promising chance for oligometastatic breast cancer. Breast. 2016;26:11-17. doi:10.1016/j.breast.2015.12.002.

80. Onal C, Guler OC, Yildirim BA. Treatment outcomes of breast cancer liver metastasis treated with stereotactic body radiotherapy. Breast. 2018;42:150-156. doi:10.1016/j.breast.2018.09.006.

81. Klement RJ, Guckenberger M, Alheid H, et al. Stereotactic body radiotherapy for oligo-metastatic liver disease - Influence of pre-treatment chemotherapy and histology on local tumor control. Radiother Oncol. 2017;123(2):227-233. doi:10.1016/j.radonc.2017. 01.013 .

82. Hong JC, Ayala-Peacock DN, Lee J, et al. Classification for long-term survival in oligometastatic patients treated with ablative radiotherapy: a multi-institutional pooled analysis. PLoS One. 2018;13(4):e0195149. doi:10.1371/journal.pone.0195149.

83. David S, Tan J, Savas P, et al. Stereotactic ablative body radiotherapy (SABR) for bone only oligometastatic breast cancer: a prospective clinical trial. Breast. 2020;49:55-62. doi:10.1016/j.breast.2019.10. 016.

84. Trovo M, Furlan C, Polesel J, et al. Radical radiation therapy for oligometastatic breast cancer: results of a prospective phase II trial. Radiother Oncol. 2018;126(1):177-180. doi:10.1016/j.radonc.2017.08.032.
Cancer Management and Research

\section{Publish your work in this journal}

Cancer Management and Research is an international, peer-reviewed open access journal focusing on cancer research and the optimal use of preventative and integrated treatment interventions to achieve improved outcomes, enhanced survival and quality of life for the cancer patient.
The manuscript management system is completely online and includes a very quick and fair peer-review system, which is all easy to use. Visit http://www.dovepress.com/testimonials.php to read real quotes from published authors. 